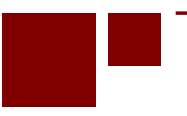

C E N T E R for RETIREMENT RES E A R C H at BOSTON COLLEGE

\title{
IS THE DROP IN FERTILITY DUE TO THE GREAT RECESSION OR A PERMANENT CHANGE?
}

\author{
Alicia H. Munnell, Anqi Chen, and Geoffrey T. Sanzenbacher \\ CRR WP 2019-7 \\ March 2019 \\ Center for Retirement Research at Boston College \\ Hovey House \\ 140 Commonwealth Avenue \\ Chestnut Hill, MA 02467
}

Tel: 617-552-1762 Fax: 617-552-0191

https://crr.bc.edu

All authors are with the Center for Retirement Research at Boston College (CRR). Alicia H. Munnell is the director of the CRR and the Peter F. Drucker Professor of Management Sciences at Boston College's Carroll School of Management. Anqi Chen is the assistant director of savings research at the CRR and Geoffrey T. Sanzenbacher is the associate director of research at the CRR. The research reported herein was made possible by the US 2050 project, supported by the Peter G. Peterson Foundation and the Ford Foundation. The findings and conclusions expressed are solely those of the authors and do not represent the views of the Peter G. Peterson Foundation, the Ford Foundation, or Boston College. The authors would like to thank Louise Sheiner, Marta Tienda, Alison Gemmill, and participants of the US2050 conferences for valuable comments.

(C) 2019, Alicia H. Munnell, Anqi Chen, and Geoffrey T. Sanzenbacher. All rights reserved. Short sections of text, not to exceed two paragraphs, may be quoted without explicit permission provided that full credit, including (C) notice, is given to the source. 


\begin{abstract}
About the Center for Retirement Research
The Center for Retirement Research at Boston College, part of a consortium that includes parallel centers at the National Bureau of Economic Research, the University of Michigan, and the University of Wisconsin-Madison, was established in 1998 through a grant from the U.S. Social Security Administration. The Center's mission is to produce first-class research and forge a strong link between the academic community and decision-makers in the public and private sectors around an issue of critical importance to the nation's future. To achieve this mission, the Center sponsors a wide variety of research projects, transmits new findings to a broad audience, trains new scholars, and broadens access to valuable data sources.
\end{abstract}

Center for Retirement Research at Boston College

Hovey House

140 Commonwealth Ave

Chestnut Hill, MA 02467

Tel: 617-552-1762 Fax: 617-552-0191

https://crr.bc.edu

Affiliated Institutions:

The Brookings Institution

Mathematica - Center for Studying Disability Policy

Syracuse University

Urban Institute 


\begin{abstract}
In the United States, the current birth rate has declined since the Great Recession. The question is whether this decline is a temporary response to the economic downturn or a drift to the lower levels seen in many other large developed countries. This paper identifies factors from the literature - both cyclical and structural - that affect the fertility rate and estimates the magnitude of these effects based on the variation across states. The cyclical analysis shows that while the total fertility rate (TFR) generally appears to be pro-cyclical, it has not rebounded with the recovery from the Great Recession. As a result, the analysis decomposes the structural factors that affect fertility - race/ethnicity, education, religion, the opportunity cost for women, and the explicit costs of raising a child. The results show that an increase in the number of women with a college education, an increase in the ratio of child care costs to income, and an increase in the female-male wage ratio can explain more than half of the decline in the total fertility rate from the period of 2001-2003 to the period of 2014-2016.
\end{abstract}




\section{Introduction}

In the United States, the current birth rate has declined since the Great Recession. The question is whether this decline is a temporary response to the economic downturn or a drift to the lower levels seen in many other large developed countries. This question could be answered relatively easily if demographers had a simple model that explained fertility patterns, but they do not. Therefore, this paper identifies factors from the literature - both cyclical and structural that affect the fertility rate and estimates the magnitude of these effects based on the variation across states to determine the extent to which fertility rates are a response to the Great Recession as opposed to underlying factors.

The discussion proceeds as follows. The first section provides a primer on the various measures of fertility and documents trends in fertility rates. At first blush, the various measures tell a mixed story of whether lower fertility is temporary or permanent. In order to examine this issue further, the second section explores the extent to which the decline in fertility can be explained by the Great Recession and the likelihood of a cyclical rebound. Although the total fertility rate (TFR) generally appears to be pro-cyclical - turning down in bad times and increasing in good times, it has not rebounded with the recovery from the Great Recession. Moreover, other measures of fertility that capture women's childbearing expectations or adjust TFR to reflect later child birth also appear to be heading lower. Thus, the case for a cyclical rebound seems like a difficult one to make. As a result, the third section turns to structural factors that affect fertility - race/ethnicity, education, religion, the opportunity cost for women as measured by the ratio of female to male wages, and the explicit costs of raising a child measured by the ratio of pre-school, housing, and in-state college tuition to median income. The exercise involves estimating - across states - the relationship between these basic factors and each state's TFR in 2001 and 2016 and then calculating the extent to which changes in these factors can explain the decline in the TFR between the two years. The results suggest that Hispanics having fewer children, an increase in the number of women with a college degree, fewer births among those with no religion, an increase in the ratio of female to male wages, and an increase in the explicit costs to raise a child more than explain the decline in the TFR since the turn of the century.

The conclusion is that the bulk of the evidence suggests that the U.S. total fertility rate is not going to bounce back to two children per woman. Looking ahead, the question is how would 
sustained low fertility rates impact the nation in the year 2050? At an individual level, the implications of low fertility are neutral, as people make their own choices about how many children to have, weighing the costs and benefits that they face. At a societal level, however, low fertility means a smaller future economy and higher tax burdens to support programs like Social Security. According to the 2018 Social Security Trustees Report, a total fertility rate of 1.8 children per woman instead of 2.0 would increase the program's 75 -year deficit by almost $\$ 2$ trillion. To avoid these negative consequences, policymakers can seek to boost fertility through more child-friendly initiatives such as affordable day care, larger tax credits, and reduced college costs. A more direct and potent option is increasing legal immigration. Policies that successfully produce a larger future workforce can yield significant economic benefits.

\section{Trends in Fertility}

Fertility is measured in a number of ways, and currently the various measures do not all tell the same story. The general fertility rate, which shows the annual rate at which women are currently having children, has been declining since the Great Recession. The total fertility rate (TFR), a measure of lifetime fertility for a hypothetical woman in her childbearing years, has also declined over the last decade. In contrast, the completed fertility rate - the number of children today's 45-49 year-olds had over their childbearing years - has been drifting up. Finally, while data on the expected number of children for women of various ages has declined slightly, expectations remain over 2 children per woman. This section discusses each of these measures in turn.

\section{General Fertility Rate}

The National Center for Health Statistics reported that, in 2017, the general fertility rate had declined to a record low of 60.2 births per 1,000 women of childbearing age (see Figure 1). This measure has grabbed the attention of the press and politicians. The question is the extent to which this pattern, in the wake of the Great Recession, reflects a decision by younger women to postpone having children rather than to have fewer children. Indeed, detailed data by age show birth rates are declining among women in their teens and 20s (see Figure 2). To the extent that with the economic recovery - women follow through with their initial plans, the birth rate should 
pick up. The measure of real interest is how many children the average women will have over the entire span of her childbearing years.

\section{Total Fertility Rate (TFR)}

One measure of lifetime fertility is captured in the TFR. The TFR for a given year is the average number of children that would be born to a woman throughout her reproductive years if she were to experience, at each point in her life, the birth rates currently observed at that age. While this definition means that the TFR is not an actual measure of lifetime fertility, it has the advantage of giving a current estimate; measures of actual completed fertility will not be available for women of current childbearing age for several decades.

The TFR fell from 1820-1975 (data in Figure 3 only from 1915), with the exception of the post-war baby boom. ${ }^{1}$ That boom explains much of the shifting financial fortunes of the Social Security program. As members of the large birth cohort born during the 1946-64 period continue to enter retirement, they are supported by relatively fewer workers, raising program costs sharply.

From 1976-1989, the TFR rose from 1.74 to about 2.00, where it hovered for almost two decades. That level is about the TFR that allows each generation to replace itself (2.08). Since a relative peak of 2.12 in 2007, however, the TFR has been trending down to 1.76 in 2017. Fertility declines in the late 1960s and early 1970s coincided with two fundamental changes that led to both later childbearing and fewer women having more than two children. One change was a sustained increase in educational attainment, particularly for women. Motivated by the desire to take advantage of their higher education, financial considerations, and the sense of satisfaction that work provides, women increased their labor force participation. As Americans became more comfortable with early childcare, more women with preschool children also started to work. The second major change was the availability of effective contraception and legal abortion, which allowed women to have children later and to have fewer children.

Figure 4, which shows age-specific fertility rates for 1978 and 2017, illustrates the shift to later childbearing. The area under the curve, which is the TFR, is virtually identical for these two years, at 1.76. But the 2017 curve has shifted substantially to the right. Figure 5 shows the pattern of the decline in the number of births since early 1970s. Women having more than three

\footnotetext{
${ }^{1}$ Preston and Hartnett (2010).
} 
children dropped sharply over this period. First and second births now make up 70 percent of all births.

\section{Completed Fertility Rate}

While the TFR is a convenient way to produce current estimates of how many children a woman will have over her lifetime, future fertility rates may differ from those assumed in the calculation. The only way to have an accurate measure of fertility is to identify the number of births that women have had at the end of their childbearing years. The completed fertility rate or cohort fertility rate is one such measure and, contrary to the TFR (a period measure), suggests no reason for concern at all. This number has actually been inching up a bit, with the most recent cohorts of 49-year-olds having averaged about 2.1 children over their lifetime. This measure, of course, is backward looking in the sense that it reports on women at the end of their childbearing years and provides limited insights on the fertility plans of younger women.

Figure 6 compares period with cohort TFR. The completed family size of actual cohorts is much less volatile than the TFR based on synthetic cohorts. The difference between the two measures can be explained by the fact that the period TFR depends on both the ages when women have children and how many children they have at those ages. During a period when childbearing ages are declining, the period TFR will be higher than the cohort and vice versa.

As shown in Figure 7, both the mean age at first birth and mean age of all births declined between the mid-1940s and 1970s when the period exceeded the cohort TFR and began rising steadily thereafter, when the cohort exceeded the period. ${ }^{2}$

\section{Fertility Expectations}

One final measure used to evaluate fertility trends is fertility expectations. If a woman's fertility intentions in her early 20 s were highly predictive of her childbearing behavior, then expectations can be used to project completed cohort fertility. So, while the TFR has not rebounded despite improving economic conditions, evidence from the National Survey of Family Growth shows that birth expectations for women ages 20-24 have remained above two children

\footnotetext{
${ }^{2}$ Preston and Hartnett (2008) estimate that the rise in the age of first birth reduced the period TFR by 0.15 children per woman over the 1980-2005 period.
} 
even after the Great Recession (see Figure 8). This consistency may suggest that the recent drop in births is a postponement rather than a decision to have fewer children.

Two points are important here, however. First, expectations among 20-24 year olds have declined by 0.17 children since the turn of the century. Second, the consensus among demographers is that intentions at younger ages are not a reliable predictor of individual or aggregate fertility, likely reflecting changes in career opportunities, marital status, partner's expectations, and subfecundity (Morgan, 2001; Morgan and Rackin, 2010). ${ }^{3}$ Indeed, comparing expectations at ages 20-24 with completed fertility for cohorts born from 1949-1964 shows that woman generally over-predict how many children they will have - the actual is around 0.3 children less than expected (see Figure 9). The same difference is evident in the National Longitudinal Survey of Youth (NLSY79). Thus, if the expectations of today's 20-24-year-olds follow the historic pattern, they would be expected to have less than two children over their lifetime.

\section{A Mixed Picture}

The picture that emerges from the discussion of the various measures of fertility is hard to decipher. On the one hand, the general fertility rate - births per thousand women - is at an alltime low, and the TFR - births to a hypothetical woman over her life span - has not recovered from the Great Recession. On the other hand, completed births remain above 2 as do expectations of lifetime births. The question, thus, is whether the current low levels of general and total fertility are simply a cyclical response to the Great Recession or a symptom of structural changes. The next section explores the extent to which the decline in fertility rates can be attributed to the cyclical factors.

\section{The Cyclical Story}

Determining whether the downturn in the total fertility rate is temporary or permanent requires assessing the extent to which it can be attributed to the Great Recession. While the 2018 Social Security Trustees Report acknowledges the lack of a post-recession bounce-back, it still assumes that the TFR will eventually recover to an ultimate level of 2.0. But the continuing

\footnotetext{
${ }^{3}$ Gemmill (2018) examines the expectations and life trajectories of permanently childless women and finds that about $44 \%$ of women who remain childless transition into not expecting children later in life.
} 
decline in the TFR through 2017 certainly raises the question of whether such a recovery will materialize.

\section{Research to Date}

Researchers have written extensively on the relationship between fertility and the state of the economy. In theory, a fall in male and female income should have different effects (Becker 1960; Mincer 1963; Becker and Lewis 1973). A decline in male income would have an unambiguous effect on fertility, as a reduction in household resources results in the decision to have fewer children. That is, lower income that accompanied an increase in the unemployment rate would be expected to lead to a decrease in the TFR. However, a decline in female income would have an ambiguous impact because it would have both an "income" and a "substitution" effect. The income effect would be similar to men and would be expected to decrease fertility. However, the substitution effect should increase fertility, as the decline in female income would lower the opportunity cost of having children. One might think that as women play a more important role as breadwinners in their families, the income effect would begin to dominate the substitution effect, so that rising unemployment would reduce fertility and vice versa.

The earliest studies in this area found a strong negative relationship between women's fertility and their employment ratios (Butz and Ward 1979) - suggesting the substitution effect was winning out. That is, good economic times were associated with a decline in fertility, presumably because the opportunity cost of bearing a child was high. A study based on U.K. data for 19501985 came to the same conclusion - an increase in woman's wages was associated with a decline in fertility (Ermisch 1988). Another early study using German data instead found no relationship between economic growth and fertility (Ermisch 1980).

Recent studies that have taken place once women entered the labor force with more regularity, however, have found a pro-cyclical effect of the economy on fertility - that is, fertility declines in times of rising unemployment and increases in recoveries. For example Mancunavich (1995) and Lee and Miller (1990) reported a pro-cyclical response, and even more recently Adsera (2004), looking at 23 OECD countries during 1960-1997, linked high unemployment to a reduction in fertility. McNowan (2003) also found a positive fertility response to prosperity. In a 2010 paper, Orsal and Goldstein, using data for 22 OECD countries for 1976-2008, found that the relationship between the change in the TFR and the change in the 
unemployment rate was again pro-cyclical - that is, good economic conditions led to a higher TFR and bad conditions to lower fertility.

The question also arises whether the reported negative short-term effects of high unemployment on fertility simply reflect a postponement of childbearing to better economic times or represent a long-term effect on completed fertility. Orsal, Karaman, and Goldstein (2010) addressed this issue by examining the relationship between a TFR-adjusted measure to account for later childbearing and the unemployment rate and found a statistically significant relationship, suggesting that unemployment not only leads to postponement in childbearing but also to fewer children. Another study (Currie and Schwandt, 2014) examined how the fertility of each cohort of women in each state related to the unemployment rate experienced by that cohort at different ages. The results showed that women in their early 20 s are most affected by high unemployment rates and that the negative effects on fertility grow over time. ${ }^{4}$

In summary, the most recent literature shows a pro-cyclical relationship between the economy and fertility, with unemployment having some lasting long-term effects.

\section{Historical Relationship between Fertility and Unemployment in the United States}

The question remains for the United States about how much of the recent drop in fertility can be explained by the Great Recession and how much of a rebound to expect. Figure 10, which relates the change in the TFR for each state with the percentage-point change in the state's unemployment rate (lagged one year), shows a clear relationship between the size of the downturn and the state's TFR. The red dots show how much each state's TFR declined in relation to how much its unemployment rate increased during the recession. The correlation was a statistically significant -0.027 - that is, when the unemployment rate increased by onepercentage point the TFR declined by 0.027 , on average.

Extending the relationship between changes in the unemployment rate and changes in the TFR to the recovery, one would expect the black dots representing the economic expansion to fall along the dashed line in the upper left-hand quadrant of Figure 10. Instead, the black dots show that the reduction of the unemployment rate during the recovery has been accompanied by

\footnotetext{
${ }^{4}$ A one-percentage-point increase in the unemployment rate experienced between ages 20-24 reduces the short-run fertility of women by 6 per 1,000 women and an overall loss of 14 per 1,000 by the end of their childbearing years driven largely by women who remain childless.
} 
a further decline in the TFR - virtually all the dots are in the lower left quadrant. That is, the relationship no longer seems to be pro-cyclical. Equally interesting, during the expansion, no apparent relationship exists between the change in employment in each state and the change in the state's TFR - that is, the estimated relationship is a straight line.

It could be that, in the United States, the TFR generally does not increase during recoveries - after all, much of the literature discussed above was based on international evidence. To understand the historical relationship between the U.S. economy and the TFR, Table 1 presents estimates of the relationship between the change in the unemployment rate (lagged one year) and the change in fertility in the 50 states over the expansions and recessions during the period 1976-2016. The equation also includes a dummy variable for each state to control for unobservable differences among states. The basic story is the TFR goes down in recessions and up in expansions, with some anomalous results for the relatively mild cycle in the early 1990s. However, the pattern for the recent recovery is very different; fertility has declined as the economy has recovered, and in fact has declined more than it did during the Great Recession.

While the equation in Table 1 shows how the business cycle relates to the fertility rate on average across states, it would be nice to know how the changes in the unemployment rate at the state level affected its TFR - that is, did harder-hit states see bigger declines. This goal can be accomplished by relating the change in the state's TFR to: 1) dummy variables for each expansion and recession as in the equation Table 1; and 2) the dummy variables interacted with the change in each state's unemployment rate. The results (see Figure 11 and Appendix Table A1) show that states that experienced a greater increase in the unemployment rate also saw a larger decline in fertility (the downward sloping lines in the lower right-hand quadrant). So the pattern experienced during the Great Recession was to be expected. Similar to other expansions, there was no relationship between the decline in the state's unemployment rate and the change in its TFR during the expansion after the Great Recession. Therefore, a flat line like those in the upper left-hand quadrant are to be expected. The big difference, however, is that the flat lines during expansions are associated with an increase in the TFR; this time the flat line is below zero. That is, the TFR declined in this expansion, and it declined by more than during the recession. 
Why Has the TFR Not Rebounded?

While it is very clear that the TFR has not rebounded as it has in previous expansions, the reasons for its persistent decline are not clear. The two possible stories are either that the taste for children has changed or that women are simply postponing having children. Indeed, the mean age of childbearing has been increasing since the mid-1960s (shown earlier in Figure 7) and appears to have taken another jump up in the wake of the Great Recession. Since the TFR is a summary statistic of the average number of births for women ages 15-49 in a given year increases in the age of childbearing can artificially depress the TFR. For an illustration, see BOX.

\section{BOX. The Effect of Later Childbearing on the TFR}

The TFR is sensitive to the timing of childbirth. Both postponement and advancement of childbirth will produce artificial fluctuations in the TFR, even if completed fertility remains constant. The table below provides a stylistic illustration. Consider a cohort of women (blue) who are ages 20-29 in year 0. They all have two children total, one in their 20s and another in their 30s. Consider another cohort of women (red) who are ages 20-29 in year 10. They also have two children total, but a decade later, one in their 30s and another in their 40s. While both cohorts of women each have 2 children, the TFR in years 10-30 will understate the total number of children that women have. The TFR will thus understate completed cohort fertility in years that women postpone childbearing and overstate cohort fertility in years that women advance childbearing.

BOX Table. Illustration of Later Childbearing on Measures of TFR and CFR

\begin{tabular}{lcccc}
\hline Age group & Year 0 & Year 10 & Year 20 & Year 30 \\
\hline $20-29$ & 1 & 0 & 0 & 0 \\
$30-39$ & 1 & 1 & 1 & 0 \\
$40-49$ & 0 & 0 & 0 & 1 \\
\hline TFR & 2 & 1 & 1 & 1 \\
\hline CFR & & & 2 & 2 \\
\hline
\end{tabular}

Source: Authors' illustration.

One way to account for the increasing age of childbirth is to look at a measure of the TFR that adjusts for postponement due to rising age of births. That is, it is possible to separate the 
TFR into two components: 1) the timing when women are having children (tempo) and 2) the number of children women have over their life course (quantum).

If both components remained unchanged, the TFR, based on projections, would equal the completed fertility rate (CFR), based on actual experience. However, as discussed above, when the age of first birth is rising, the actual TFR falls below the CFR. Theoretically, if the only change in fertility is the timing of births, the relationship between the cohort measure of $C F R$ and the period measure of TFR can be shown as:

$$
C F R_{t}=\frac{T F R_{t}}{\left(1-r_{t}\right)}
$$

where $r_{t}$ represents the rate at which the average age of childbearing, for all births, is increasing for each successive cohort. ${ }^{5}$ For example, if the average age of childbearing were 27 for women born in 1960 but 27.1 for women born in 1961, this average increase of 1.2 months $\left(r_{t}=\frac{1}{10}\right.$ years) would depress the TFR by 10 percent relative to the CFR for the cohort (Goldstein, Sobotka, and Jasolioniene 2009; Bongaarts and Feeney 1998).

Current tempo-adjusted measures of fertility are based on Bongaarts and Feeney $(1998,2000)$, which incorporate changes in the age of childbirth for each birth order. Adjusting for timing by birth order is important because higher order births occur at older ages when the woman has less time for delay. Following Bongaarts and Feeney (2000) and Goldstein, Sobotka, and Jasolioniene (2009), the tempo-adjusted TFR for birth order $i$ (where $i=1,2,3, \ldots$ represents the first birth, second birth, third birth, etc.) in calendar year $t$ can be written as:

$$
\operatorname{adjTFR} R_{i, t}=\frac{T F R_{i, t}}{\left(1-r_{i, t}\right)}
$$

\footnotetext{
${ }^{5}$ Ryder (1964).
} 
Here, the timing adjustment factor $r_{i, t}$ is defined as:

$$
r_{i, t}=\frac{\left[M_{i, t+1}-M_{i, t-1}\right]}{2}
$$

where $M_{i, t}$ is the average age of the mother at birth order for birth order $i$ in calendar year $t .^{6}$ Using this approach, it is possible to construct a tempo-adjusted fertility rate for the period 19762016 (see Figure 12). Since the entire period under consideration is one where the average age of birth is rising, the tempo-adjusted TFR is generally higher than the reported TFR. The exceptions are the periods 1988-91 and around the Great Recession when the average age of childbirth decreased slightly. Importantly, the decline in the tempo-adjusted rate in recent years suggests that the taste for children may be changing.

The tempo-adjustment attempts to provide a measure of fertility in the absence of postponement; as such, it aims to provide a pure quantum effect. This interpretation, however, relies on strong assumptions - mainly, that delays in childbearing are the same across all ages and increase linearly over time. Since declines in births tend to occur at younger ages and delays at older ages are subject to a biological limit, demographers caution against interpreting higher tempo-adjusted TFR directly as higher completed cohort fertility (Lesthaeghe and Willems 1999; Frejka Sardon 2009). Critics argue that while delays in childbearing do artificially depress the TFR, these postponements are only partially offset by births at older ages. In other words, fertility postponed is also, to some extent, fertility foregone.

Completed - or cohort - fertility is the true measure of how many children women are actually having. The problem is that the data are not available; the most recent information on completed births of 45-49-year-olds says little about the plans of those in their 20s and 30s. As a result, demographers have to make projections. Traditionally, they have based their projections on age-specific fertility rates observed in the last period. If fertility rates are increasing or decreasing, however, this approach will understate or overstate the likely completed fertility rates.

\footnotetext{
${ }^{6}$ Since the adjusted TFR has large annual fluctuations, the series is smoothed using a three-year moving average, as shown in Goldstein et al. (2009).
} 
Indeed birth rates by age have shown some distinct trends (see Figure 13). Birth rates among those in their teens and ages 20-24, and to a lesser extent ages 25-29, fell sharply after the Great Recession. While births among mothers ages 30-34 and 35-39 have increased, they have not increased enough to offset the decline among younger women.

Myrskyla et al. (2013) suggest estimating cohort fertility by extrapolating the age-specific trends of the last five years into the future for five years and then freezing those rates for projection purposes. They argue that such a procedure is not only simpler than some alternative approaches but also would have been more accurate historically.

The extrapolation model forecasts age-specific fertility at age $a$ and calendar year $t$ as follows:

$$
f_{a, t}=f_{a, t-1}+\hat{\beta} \delta_{a}+\hat{c}
$$

where $\delta_{a}$ is the average annual change in fertility rates in the last five years and $\hat{\beta}, \hat{c}$ are the coefficient on $\delta_{a}$ and the constant respectively, obtained by regressing $f_{a, t}-f_{a, 2015}$ on $\delta_{a}{ }^{7}$ The CFR is thus the sum of all the extrapolated age-specific fertility rates for each cohort at each age:

$$
\sum_{a=15}^{49} f_{a, t}
$$

The results are shown in Figure 14. The completed fertility rate is for the cohort born 27 years earlier to match the average age of births and line up with the TFR. Regardless of whether the projected cohort fertility is based on adopting age-specific fertility rates observed in the last period or extrapolating the trend of the last five years into the future, the completed fertility rate appears likely to decline.

The conclusion that emerges from this section is that while historically the TFR appears to have been pro-cyclical - turning down when the economy falters and increasing when it recovers - that relationship has not held in the most recent recovery when the TFR has continued to decline. Moreover, measures that try to get at the number of children that a woman is likely

\footnotetext{
7 This formulation is also used by Lee and Carter (1992) for modeling log-mortality rates over time and by Lee (1994) and Lee and Tuljapurkar (1994) for modeling period fertility.
} 
to have over her lifetime are also heading lower. Both the tempo-adjusted TFR - based on synthetic cohorts - and the projected completed fertility rate are lower now than at the beginning of the century. While no one knows what will happen in the future, the case for a cyclical rebound seems like a difficult one to make.

\section{The Structural Story}

If the case for a cyclical rebound is difficult to make, then the fundamental factors that determine the U.S total fertility rate must have changed. The challenge is to identify the determinants of fertility and report how changes in those determinants have affected the total fertility rates. The problem is that researchers, who come from a wide range of disciplines, do not appear to have a generally accepted framework for analyzing fertility.

From an economic perspective, it is not clear why people have children; they are extremely costly in terms of time, anxiety, and money. Children may have offset some of these costs by working on the farm in an agrarian society, but agriculture has been only a small part of the economy for more than a century. At one point women had little control over their fertility, but that situation changed with the advent of the pill and the availability of legal abortion. So conception is a purposeful decision for many women. Having children may seem like the natural step to cement a marriage, but about 40 percent of children in the United States are born outside of wedlock. Moreover, women now have many opportunities outside the home, so having children is costly in terms of work. Yet, despite gaining control of their reproductive rights, their increasing opportunities outside marriage, and the decline in marriage itself, women continue to have babies.

Economists generally explain the demand for children in terms of Becker's (1960) neoclassical theory, where the decision to have a child is a rational choice about the economic costs and benefits of children, subject to an income constraint and to individuals' preferences for children (as opposed to other goods). Thinking of children as a consumption good leads to the prediction that higher-income families would have more children.

That prediction flies in the face of the facts. Researchers find a consistent negative relationship between income and fertility in time series studies, across countries, and across individuals. For the United States, Jones and Tertilt (2008) report a negative cross-sectional relationship between income and fertility for the 30 birth cohorts between 1830 and 1960 that 
remained relatively constant at -0.30 . One explanation is that the price of children is largely time, and hence children are more expensive for parents with higher wages or that higher-wage people have a higher demand for child quality, making quantity more expensive and therefore those parents want fewer children. ${ }^{8}$ Another explanation is that women differ in their preferences for children and generate income differences by working fewer hours and earning lower wages (as a result of less formal education or on-the-job training).

In the end, no single economic model has been adopted to explain fertility and no general model incorporates the perspective of all the relevant disciplines. Hence, the only option is to explore results from the empirical literature that report correlates with fertility across time, individuals, and countries.

\section{Correlates with Fertility}

The empirical approach adopted here is to look across states in 2001 and estimate the relationship between the most basic correlates with fertility and then re-estimate that relationship in 2016 in an attempt to explain the decline in the total fertility rate from 2.03 children per woman to 1.82 in 2016. Researchers have identified many factors that could affect fertility such as political climate (Lesthaeghe and Neidert 2006), social programs (Moffitt, 1999), or abortion legislation (Klerman 1999), but we view these considerations as derivative of the underlying characteristics - race/ethnicity, education, and religion - of the population, which establish the taste for children. ${ }^{9}$ In addition, the nature of work available reflects the opportunity costs of having children. Therefore, the following discussion focuses on four factors: race/ethnicity, education, religion, and the ratio of female to male wages.

\footnotetext{
${ }^{8}$ Becker (1960) appears to argue the demand for child quality should increase greatly as income rises but the demand for quantity of children only slightly, and the observed strong negative relationship between fertility and income is a missing variables issue.

${ }^{9}$ A 1999 review (Moffitt) on the relationship between welfare payments and fertility showed a modest positive effect of benefit payments on fertility. Klerman (1999) finds modest effects on fertility of interstate differences in access to abortion and of Medicaid payments for abortion. In terms of culture, Lesthaeghe and Neidert (2006) performed a factor analysis and found that states with late marriage and higher abortion rates had lower fertility and a high correlation between "this demographic cluster and the percent voting for George W. Bush in 2004." These findings suggests important variation in the underlying values that manifests itself in both family and political domains.
} 
Ethnicity. Traditionally U.S. fertility has varied by race and ethnicity (see Figure 15), with Hispanics having the highest rates, followed by blacks, and then whites. By 2001, however, the TFR for blacks had dropped noticeably to the national average. In contrast, the TFR for Hispanics remained high. Between 2001 and 2016, however, fertility among Hispanics declined sharply and seems to be converging rapidly to the rate of whites and blacks. This convergence has coincided with the decline in immigration since the Great Recession, largely a result of the reversal of unauthorized immigration (Passel, Cohn, and Gonzalez-Barrera 2012). The recent decline in Hispanic fertility could persist since U.S.-born Hispanics have lower birth rates than those born in other countries, and births among foreign-born Hispanics are also declining. ${ }^{10}$

Importantly, the difference in fertility between whites and Hispanics persists even after controlling for education (see Table 2). College-educated Hispanic women who are near the end of their childbearing years had more children than college-educated whites. The same pattern occurs for women with some college and those with high school or less.

Although fertility among Hispanics declined the most dramatically since the Great Recession, the fertility rate among other races also dropped (Figure 15). Despite secular decline, fertility rates in the U.S. are still among the highest in OECD countries. Between 2001 and 2015, the U.S. moved from \#1 to \#5 in international comparisons (see Figures 16a and 16b). This suggests that relatively higher fertility rate in the U.S. did not rest solely on the high fertility rates of minorities.

Education. Women with more education traditionally have fewer children. The direction of causation is unclear. Women with a taste for children could not pursue educational and employment opportunities or women with a taste for career could decide not to have as many children. In any event, as Figure 17 shows, near the end of their childbearing years (40-44) women with higher levels of educational attainment have averaged fewer children than their lesseducated counterparts. ${ }^{11}$

This pattern is important because the percentage of women with a college education or more has increased dramatically in recent years. By 2016, more than 40 percent of women fell

\footnotetext{
${ }^{10}$ See Camarota and Zeigler (2017). The TFR among native-born Hispanics declined from 2.17 in 2006 to 1.85 in 2015. The TFR among foreign-born Hispanics declined from 2.90 to 2.38 during the same period.

${ }^{11}$ Recent CPS data show a fall in childlessness and an increase in family size among recent cohorts of highly educated women (Livingston 2015).
} 
into this highly educated group, while those with a high school education or less dropped sharply (see Figure 18). This shifting mix puts downward pressure on the TFR.

Interestingly, schooling appears to have become less closely associated with fertility in recent years, despite the fact that educational differentials in women's earnings became much steeper (Blau 1998; Goldin and Katz 2007). Recent surveys show that young women with a college education expect to have more than two children just like those with less education (see Figure 19). Although they are currently behind in terms of childbearing, they expect to catch up as they get older. Part of the explanation for more childbearing among well-educated women may be that as childcare becomes more available, they can substitute paid help for their own time in raising children. In addition, since employers want to keep valuable employees, collegeeducated women could expect the least career disruption from childbearing (Dex et al. 1996; Waldfogel 1997).

Religion. An extensive literature explores the relationship between religion and fertility in the United States. Early studies on variations in fertility across religions focused on differences between Catholics and Protestants (Freedman et al., 1959; Ryder and Westoff, 1971; Whelpton et al., 1966). These studies attributed the higher fertility rates among Catholics to doctrines prohibiting birth control as well as educational and income differences from immigrant Catholic populations. Other religious groups with pro-natalist doctrines also have higher fertility rates, most notably Mormons and fundamentalist Protestants (Heaton 1986, Hout et al. 2001).

McQuillian (2004) provides a framework on how religious identities can affect fertility. First, religions set moral codes and values about specific fertility-related behavior such as sexuality, gender roles, and the place of a family in society. Second, religious groups enforce conformity through social influence or sanctions. In the end, religion becomes akin to culture and constitutes an important aspect of individual identity.

Indeed, the most recent National Survey of Family Growth (which asks "What religion are you now, if any?") shows observable differences in fertility across different religions for women at the end of their childbearing years. The number of children per woman varies from 2.6 for Fundamentalist Christians to 1.6 for "other religion", which consists of non-Christians (see Figure 20). 
Importantly, the 23 percent of women who identify as having no religion had the fewest children over their lifetime (see Table 3). Indeed, demographers have concluded that religious service attendance is highly positively correlated with fertility in both the United States and Europe (Frejka and Westofff 2006; Philipov and Beghammer 2007). American churches, in particular, are entrepreneurial and offer a variety of activities to attract parishioners (Preston and Hartnett, 2009). It may be the opportunity for parents to interact with other families and receive moral support that affects fertility more than religiosity itself (Wuthnow 2005).

Unfortunately, surveys of individual religious affiliation are not available at the state level. So the data on religion at the state level (used in the regression analysis in Figure 23 and Table A2) come from a survey of religious congregation membership conducted by the Association of Statisticians of American Religious Bodies. Congregations of 236 religious groups in each county of the United States were asked to identify all members, including full members, their children and the estimated number of other participants who are not considered members. The percentage with no religious affiliation is then calculated by dividing the affiliated by the state's population and subtracting from 100 percent. That calculation shows that, nationwide, 51 percent of the population were not members of a religious congregation. This figure is significantly higher than the 23 percent of women between the ages of 15 and 45 in the National Survey of Family Growth that reported no religious affiliation. Table 4 attempts to reconcile the conflicting estimates. Adding to those who report no religious affiliation, those who never attend services raises the percentage to 33 percent. Adding to those who report no religious affiliation, those who attend services less than twice a year raises the percentage to 44 percent. Thus, the conclusion from the Religious Census that almost half the population does not belong to a congregation does not seem inconsistent with the responses from the NSFG.

Ratio of Female to Male Wages. While the previous three categories - ethnicity, education, and religion - affect women's attitudes towards having children, the next two factors attempt to get at the cost of children. The opportunity costs of having children are higher for women with better labor market options (for example, see Preston and Hartnett 2009). ${ }^{12}$ While

\footnotetext{
${ }^{12}$ Preston and Hartnett (2009) combined individual level variables from the 2002 NSFG with four aggregate level economic indicators from the 2000 Census to identify the determinants of fertility for the 280 largest metropolitan areas. The economic indicators included the median earnings of male and female full-time, full-year workers; the unemployment rate; and the median value of owner-occupied housing. The individual level variables were:
} 
labor market opportunities clearly increase with educational attainment, they are also affected by how much women earn in the labor market relative to men. Figure 21 presents the ratio of female to male wages in each state - the higher it is the more women in the state earn relative to men. ${ }^{13}$ This variable may be important in a couple's fertility decision, since a high wage ratio implies the family would give up a higher share of its income if a baby led the woman to take time off. In 2001, this ratio varied from a high of 86 percent in Washington, DC to a low of about 50 percent in Wyoming. ${ }^{14}$

Ratio of Child Cost-to-Income. In addition to opportunity costs, families also face the explicit costs of raising a child. Some of the major components include expenses related to preschool, housing, and college. As a rough estimate of the cost of raising a child, we construct an index that compares the total cost for two years of preschool, the median home price, and the tuition for four years at an in-state college with the median income for households of childbearing age. ${ }^{15}$ The expectation is that a higher cost ratio will be negatively related to the TFR. Figure 22 presents the cost ratio by state; in 2001, this ratio ranged from a high of 5.4 in California to a low of 2.3 in Oklahoma.

The costs of raising a child, women's relative wage in the state along with the percentage of women who are Hispanic (separated by native-born and foreign-born) or black, the percentage of women who are college-educated or more, and the percentage of the population that does not belong to a congregation are used to explain the variation in fertility rates across states. ${ }^{16}$

\footnotetext{
educational attainment of the interviewee's mother; the religion in which the interviewee was raised; and whether or not her parents' marriage was intact when she was 18 . The coefficients on female earnings were large, significant, and negative while the coefficient on male earnings was large, significant, and positive.

${ }^{13}$ The ratio is calculated by first dividing earnings by hours worked to determine wages, to adjust for any potential differences in hours worked between men and women. Next, aggregate wages are calculated by gender. The ratio is therefore aggregate wages for all working women divided by the aggregate wages for all working men in given state and year.

${ }^{14}$ Controlling for differences in education, in addition to hours, shows an almost identical result.

${ }^{15}$ Pre-school cost data combines estimates from Urban Institute, National Survey of American Families (1999-2002) and Childcare Aware, National Data System for Child Care (2014-2016). Housing data is from Zillow Home Values. The cost of in-state tuition is U.S. Department of Education, National Center for Education Statistics, Digest of Education Statistics. The cost of two years or pre-school, the median home price, and four years of instate tuition are added together and divided by the median household income. The ratio is a multiple of median annual household income.

${ }^{16}$ The analysis separates Hispanics into native-born and foreign-born since the two groups have different effects on the U.S. fertility rate.
} 


\section{Regression Results}

As noted, the empirical approach is to look across states in 2001 and estimate the relationship between the most basic correlates of fertility and then to re-estimate that relationship in 2016 in an attempt to explain the decline in the TFR over the 2001-2016 period from 2.03 to 1.82. The goal is to see if underlying factors that have nothing to do with the Great Recession can explain the decline in the nation's TFR.

To analyze the impact of these basic factors - race/ ethnicity, education, religion, and the opportunity cost and explicit cost of children - on the decline in the TFR, the paper uses a Oaxaca-Blinder (1973) decomposition where each state represents an observation and its TFR the outcome of interest. The Oaxaca-Blinder decomposition seeks to disentangle two ways in which these variables could lead to a decline in TFR. The first way is a change in the value of the variable itself. For example, the Hispanic share of the U.S. population increased from 20012016 (see Table 5). Since Hispanics have higher fertility than non-Hispanics, this change would serve to increase fertility relative to a world in which the Hispanic population remained constant. The second way these variables can impact the TFR is if their relationship to fertility actually changes over time. For example, Figure 15 clearly illustrated that the TFR of Hispanics dropped from 2001-2016, although it still remained above that of blacks and of whites. This declining relationship would cause the TFR to drop relative to a world in which Hispanics continued to have fertility consistent with their higher 2001 levels.

Carrying out the decomposition involves running two regressions of the TFR in a state controlling for the factors outlined above, one in the initial period and one in the more recent period. To avoid having the estimates unduly affected by just one year of data, the years 2001$2003($ TFR $=2.03)$ are used as the initial period and 2014-2016 $($ TFR $=1.84)$ as the more recent period. Results from the two regressions are shown in Figure 23 (see Appendix Table A2 for standard errors). ${ }^{17}$ When significant, the results are as expected; states with a higher Hispanic population have a higher TFR and states with highly educated women, a higher share of people who are not church members, a higher ratio of female to male wages, or a higher ratio of child

\footnotetext{
${ }^{17}$ Table A2 provides other estimates that combines the nativity of Hispanic population, excludes the cost ratios, and calculates education-adjusted female to male wage ratios.
} 
costs to income are associated with lower fertility. ${ }^{18}$ Importantly, the difference between the two colored bars shows that the strength of the positive relationship between Hispanic and the TFR decreased over this period while the effect of being non-religious became more negative. Both of these effects would tend to push TFR down.

The first decomposition exercise assumes that the coefficients from the two regressions are fixed at the average and predicts what would have happened to TFR if the proportion of the variables changed as they did between 2001-2003 and 2014-2016. The results are shown in Figure 24 (gray bars, see Appendix Table A3 for standard errors). The results indicate that the increase in the share of states' populations that are native-born Hispanic would have actually increased TFR by a statistically significant 0.02 (relative to the 0.19 decline). However, the increase in women with a college education, the increase in the ratio of female to male wages, and the increase in the ratio of child costs to income all served to significantly decrease TFR, by $0.05,0.04$, and 0.01 respectively. Since the share of the population that is foreign-born Hispanic, non-religious or black did not change very much, the change in the level of these variables did not impact the TFR significantly.

The second exercise assumes that the level of each variable is fixed at the average of the two periods and predicts what would have happened to TFR if the coefficients changed as they did between 2001-2003 and 2014-2016. Figure 24 (red bars, see Appendix Table A3 for standard errors) indicates that only two of the results are statistically significant in this exercise, but they have a large effect in predicting a decrease in TFR between the early 2000s and today. The first is the fact that Hispanics are having fewer children, which explains a drop of 0.08 in the TFR. The second is the fact that the non-religious are having fewer children, which explains a drop of 0.19 . Working in the other direction - although not statistically significant - is that both cost ratios are less predictive of low fertility than they used to be.

In summary, the TFR declined between 2001 - well before the Great Recession - and 2016 - well after the Great Recession. State regressions suggest that fertility is positively related to the percentage of women who are Hispanic and negatively related to the percentage of women with college or more, the lack of religion, and a high ratio of female to male wages. Some of these factors affect the fertility rate between 2001 and 2016 through changes in the proportions -

\footnotetext{
${ }^{18}$ Only the coefficient on native-born Hispanics is significant since the foreign-born Hispanics represent only a
} small share of the population, which remain relatively constant between 2001 and 2016. See Table 5 for details. 
that is, directly through the variables included in the regression - and some through changes in the coefficient - that is, through the estimated effects of the variable. Specifically, the effect of education works through the change in the proportion of women with college, and the effect of foregone wages works through changes in the ratio of female-to-male wages. In contrast, the share of the native-born women who are Hispanic does not change much but the coefficient does as Hispanics have fewer children. Similarly the share of the population non-religious does not change but the impact of being non-religious - that is, the coefficient - has a much larger negative effect on fertility. The sum of all these effects suggests that it is not necessary to appeal to the Great Recession to explain the decline in U.S. fertility in the $21^{\text {st }}$ century.

\section{Conclusion}

The question explored in this study is whether the decline in U.S. fertility since the Great Recession is the temporary response to the economic downturn or a slow drift to the levels seen in many other large developed countries.

The analysis of the relationship between the economy and the total fertility rate confirms that the performance of fertility in the current expansion is anomalous. While historically the TFR appears to have been pro-cyclical - turning down when the economy falters and increasing when it recovers - that relationship has not held in the most recent recovery when the TFR has continued to decline. Moreover, other measures that try to get at the number of children that a woman is likely to have over her lifetime are also heading lower. Both the tempo-adjusted TFR - based on synthetic cohorts - and the projected completed fertility rate are lower now than at the beginning of the century. Thus, the case for a cyclical rebound seems like a difficult one to make.

At the same time, the percentage of women who are Hispanic, the percentage of women with a college education, the percentage of the population with no religion, and the ratio of female to male wages explain much of the variation in the total fertility rates across states in both 2001 and 2016. The decline in the fertility rate between 2001 and 2016, it appears, can be more than explained by Hispanics having fewer children, an increase in the number of women with a college degree, fewer births among those with no religion, and an increase in the ratio of female to male wages. One might conclude that it is not necessary to appeal to the Great Recession to explain the decline in U.S. fertility in the $21^{\text {st }}$ century. 
Overall, then, it appears that fertility may bounce back somewhat as Millennials, who got a late start, begin to have children, but it seems likely that U.S. women will have completed fertility of less than two children going forward.

What are the implications of today's low-fertility environment for the United States a few decades from now, in 2050? The impact will be felt on two levels: individual and societal. At the individual level, the choice of how many children to have reflects each person's unique preferences, and how they respond to the mix of costs and benefits they face. In this context, a lower fertility rate is simply the aggregate result of all these personal choices and not a negative development per se. Indeed, people with fewer children can devote more time and energy to their careers and other pursuits and enjoy higher per-person consumption. At the societal level, though, lower fertility has serious consequences: a smaller future workforce will result in slower overall economic growth and higher tax burdens to support pay-as-you-go programs such as Social Security. According to the 2018 Social Security Trustees Report, a total fertility rate of 1.8 children per woman instead of 2.0 would increase the program's 75 -year deficit by 0.41 percent of taxable payrolls or a present value of almost $\$ 2$ trillion.

If policymakers want to avoid the consequences of a low-fertility future, they have two levers at their disposal. First, they could adopt pro-fertility policies that reduce the costs related to raising children. Such policies could include making child care more affordable, offering larger tax credits, strengthening parental leave policies, and reducing the cost of college. Second, and more directly, policymakers could substantially increase legal immigration - an option that would have both a greater and more immediate impact. Policies that successfully produce a larger future workforce have the potential to yield significant economic benefits. 


\section{References}

Autor, David, David Dorn, and Gordon Hanson. 2018. "When Work Disappears: Manufacturing Decline and the Falling Marriage Market Value of Young Men." Working Paper 23173. Cambridge, MA: National Bureau of Economic Research.

Becker, Gary S. 1960. "An Economic Analysis of Fertility." In Demographic and Economic Change in Developed Countries, 209-240. New York City, New York: Columbia University Press.

Becker, Gary S. and H. Gregg Lewis. 1973. "On the Interaction between the Quantity and Quality of Children." Journal of Political Economy 81(2): S279-S288.

Blau, Francine D. 1998. "Trends in the Well-Being of American Women, 1970-1995." Journal of Economic Literature 36(1) 112-165.

Blinder, Alan S. 1973. "Wage Discrimination: Reduced Form and Structural Estimates." Journal of Human Resources 8(4) 436-455.

Bongaarts, John and Griffith Feeney. 1998. "On the Quantum and Tempo of Fertility." Population and Development Review 24(2) 271-291.

Bongaarts, John and Griffith Feeney. 2000. "On the Quantum and Tempo of Fertility: Reply." Population and Development Review 26(3) 560-564.

Butz, William P. and Michael P. Ward. 1979. "The Emergence of Countercyclical US Fertility." The American Economic Review 69(3) 318-328.

Camarota, Steven, and Karen Zeigler. 2015. "The Declining Fertility of Immigrants and Natives." Center for Immigration Studies.

Childcare Aware, National Data System for Child Care, 2014-2016. Arlington, VA

Centers for Disease Control and Prevention, National Survey of Family Growth, 2002, 20062010, 2011-2013, and 2013-2015. Atlanta, GA.

Centers for Disease Control and Prevention, U.S. National Vital Statistics Reports, 1976-2017. Atlanta, GA.

Centers for Disease Control and Prevention, National Center for Health Statistics, Vital Statistics Natality Birth Data, 1976-2016. Atlanta, GA.

Currie, Janet and Hannes Schwandt. 2014. "Short-and Long-Term Effects of Unemployment on Fertility." Proceedings of the National Academy of Sciences 111(41) 14734-14739. 
Elder, Todd E., John H. Goddeeris, and Steven J. Haider. 2010. "Unexplained Gaps and OaxacaBlinder Decompositions." Labour Economics 17(1) 284-290.

Ermisch, John F. 1980. "Time Costs, Aspirations and the Effect of Economic Growth on German Fertility." Oxford Bulletin of Economics and Statistics 42(2) 125-143.

Ermisch, John. 1988. "Econometric Analysis of Birth Rate Dynamics in Britain." The Journal of Human Resources 23(4) 563-576.

Freedman, Ronald, Paskal K. Whelpton, and Arthur A. Campbell. 1959. Family Planning, Sterility and Population Growth. New York: McGraw-Hill Book Company, Inc.

Frejka, Tomas and Charles F. Westoff. 2008. "Religion, Religiousness and Fertility in the US and in Europe." European Journal of Population 24(1) 5-31.

Frejka, Tomas and Jean-Paul Sardon. 2009. "Contemporary Childbearing Trends in LowFertility Countries." XXVIth IUSSP International Population Conference.

Gemmill Alison. 2018. "From Some to None? Fertility Expectation Dynamics of Permanently Childless Women." Demography: 1-21.

Goldin, Claudia and Lawrence F. Katz. 2007. "Long-Run Changes in the US Wage Structure: Narrowing, Widening, Polarizing.” Working Paper No. 13568. Cambridge, MA: National Bureau of Economic Research.

Goldstein, Joshua R., Tomáš Sobotka, and Aiva Jasilioniene. 2009. "The End of "lowest-low" Fertility?" Population and Development Review 35(4) 663-699.

Gustafsson, Siv S., Cecile MMP Wetzels, Jan Dirk Vlasblom, and Shirley Dex. 1996. "Women's Labor Force Transitions in Connection with Childbirth: A Panel Data Comparison between Germany, Sweden and Great Britain." Journal of Population Economics 9(3) 223-246.

Heaton, Tim B. 1986. "How does Religion Influence Fertility?: The Case of Mormons." Journal for the Scientific Study of Religion 25(2) 248-258.

Hout, Michael, Andrew Greeley, and Melissa J. Wilde. 2001. "The Demographic Imperative in Religious Change in the United States." American Journal of Sociology 107(2) 468-500.

Jones, Larry E. and Michele Tertilt. 2008. "Chapter 5: An Economic History of Fertility in the United States: 1826-1960." In Frontiers of Family Economics, 165-230. Bingley, UK: Emerald Group Publishing Limited.

Klerman, Jacob Alex. 1999. "US Abortion Policy and Fertility." American Economic Review 89(2) 261-264. 
Kogut, Edy Luiz. 1974. “The Economic Analysis of Fertility: A Study for Brazil.” Population and Employment. Working Paper No. 7. Geneva: World Employment Programme at ILO.

Lee, Ronald D. 1994. "The Formal Demography of Population Aging, Transfers, and the Economic Life Cycle." In Demography of Aging, 8-49. Washington, DC: National Academy Press.

Lee, Ronald D. and Lawrence R. Carter. 1992. "Modeling and Forecasting US Mortality." Journal of the American Statistical Association 87(419) 659-671.

Lee, Ronald D. and Shripad Tuljapurkar. 1994. "Stochastic Population Forecasts for the United States: Beyond High, Medium, and Low." Journal of the American Statistical Association 89 (428) 1175-1189.

Lee, Ronald D., and Timothy Miller. 1990. "Population Growth, Externalities to Childbearing, and Fertility Policy in Developing Countries." The World Bank Economic Review 4 (1): 275-304.

Lesthaeghe, Ron and Paul Willems. 1999. "Is Low Fertility a Temporary Phenomenon in the European Union?" Population and Development Review 25(2) 211-228.

Lesthaeghe, Ron J. and Lisa Neidert. 2006. "The Second Demographic Transition in the United States: Exception or Textbook Example?" Population and Development Review 32(4) 669-698.

McNown, Robert. 2003. "A Cointegration Model of Age-Specific Fertility and Female Labor Supply in the United States." Southern Economic Journal 70(2) 344-358.

McNown, Robert. 2003. "A Cointegration Model of Age-Specific Fertility and Female Labor Supply in the United States." Southern Economic Journal 70(2) 344-358.

McQuillan, Kevin. 2004. "When Does Religion Influence Fertility?" Population and Development Review 30(1) 25-56.

Mincer, Jacob. 1963. "Opportunity Costs and Income Effects.” In Measurement in Economics, edited Carl F. Christ, et al. Stanford, CA: Stanford University Press.

Moffitt, Robert A. 1999. "Demographic Change and Public Assistance Expenditures.” Working Paper No. 6995. Cambridge, MA: National Bureau of Economic Research.

Morgan, S. Philip and Heather Rackin. 2010. "The Correspondence between Fertility Intentions and Behavior in the United States." Population and Development Review 36(1) 91-118.

Morgan, S. Philip. 2001. "Should Fertility Intentions Inform Fertility Forecasts.” U.S. Census Bureau Conference: The Direction of Fertility in the United States. 
Myrskylä, Mikko, Joshua R. Goldstein, and Yen-hsin Alice Cheng. 2013. "New Cohort Fertility Forecasts for the Developed World: Rises, Falls, and Reversals." Population and Development Review 39(1) 31-56.

Neumark, David. 2004. "Employers' Discriminatory Behavior and the Estimation of Wage Discrimination." In Sex Differences in Labor Markets, 163-177. London, UK: Routledge.

Oaxaca, Ronald. 1973. "Male-Female Wage Differentials in Urban Labor Markets." International Economic Review 14(3) 693-709.

OECD. Fertility Rates (Indicator). 2001 and 2015. Paris: OECD.

Orsal, Deniz Dilan Karaman and Joshua R. Goldstein. 2010. "The Increasing Importance of Economic Conditions on Fertility." Working Paper 2010-014. Rostock, Germany: Max Planck Institute for Demographic Research.

Pew Hispanic Center. 2012. "Net Migration from Mexico Falls to Zero—and Perhaps Less."

Philipov, Dimiter and Caroline Berghammer. 2007. "Religion and Fertility Ideals, Intentions and Behaviour: A Comparative Study of European Countries." Vienna Yearbook of Population Research 5 271-305.

Preston, Samuel H. and Caroline Sten Hartnett. 2009. "The Future of American Fertility." Working Paper 14498. Cambridge, MA: National Bureau of Economic Research.

Preston, Samuel H. and Caroline Sten Hartnett. 2010. "The Future of American Fertility." In Demography and the Economy, 11-36. Chicago, IL: University of Chicago Press.

Ryder, Norman B. 1964. "The Process of Demographic Translation." Demography 1(1) 74-82.

Schaller, Jessamyn. 2016. "Booms, Busts, and Fertility Testing the Becker Model using GenderSpecific Labor Demand." Journal of Human Resources 51(1) 1-29.

Urban Institute, National Survey of American Families, 1999-2002. Washington, D.C.

U.S. Bureau of Labor Statistics, National Longitudinal Survey of Youth, 1979- 2016. Washington, D.C.

U.S. Census Bureau, American Community Survey, 2001-2016. Washington, D.C.

U.S. Census Bureau, Current Population Survey Annual Social and Economic Supplement, 1980-2017. Washington, D.C.

U.S. Census Bureau, Current Population Survey Fertility Supplement, 1976-2016. Washington, D.C. 
U.S. Department of Education, National Center for Education Statistics, Digest of Education Statistics, 2001-2016 Washington, D.C.

U.S. Religion Census, Religious Congregations and Membership Study, 2010. Lenexa, KS.

U.S. Social Security Administration. 2017. "The 2017 Annual Report of the Board of Trustees of the Federal Old-Age and Survivors Insurance and Federal Disability Insurance Trust Funds." Washington, DC.

Waldfogel, Jane. 1997. "The Effect of Children on Women's Wages." American Sociological Review 62(2) 209-217.

Westoff, Charles F. and Norman B. Ryder. 1971. "Family Limitation in the United States."

Whelpton, Pascal K., Arthur A. Campbell, and John E. Patterson. 1966. Fertility and Family Planning in the United States. Princeton: Princeton University Press.

Wuthnow, Robert. 2005. "Democratic Renewal and Cultural Inertia: Why our Best Efforts Fall Short." Sociological Forum 20(3) 343-367.

Zillow Research, Zillow Home Value Index, 2001-2016. Seattle, WA. 
Table 1. Effect of Business Cycles on the Change in TFR, 1976-2016

\begin{tabular}{lc}
\hline Variable & Coefficient \\
\hline 1976-1980 expansion & $0.231^{* * *}$ \\
& $(0.0703)$ \\
1980-1982 recession & -0.0266 \\
& $(0.0445)$ \\
1982-1990 expansion & $0.353^{* * *}$ \\
& $(0.135)$ \\
1990-1991 recession 1 & -0.0289 \\
& $(0.0433)$ \\
1991-2000 expansion & -0.0696 \\
& $(0.0616)$ \\
2001 recession & $-0.0731^{*}$ \\
& $(0.0434)$ \\
2002-2007 expansion & 0.0368 \\
& $(0.0434)$ \\
2007-2009 recession & $-0.157^{* * *}$ \\
& $(0.0463)$ \\
2009-2016 expansion & $-0.227^{* * *}$ \\
& $(0.0456)$ \\
\hline Observations & 458 \\
R-squared & 0.439 \\
\hline
\end{tabular}

${ }^{1}$ Not all states experienced the 1990-1991 recession. The equation also includes a dummy variable for each state to control for unobservable differences among states.

Note: Robust standard errors in parentheses. ${ }^{* * *} \mathrm{p}<0.01$.

Source: Authors' calculations.

Table 2. Total Number of Children for Women Ages 40-44, by Ethnicity and Educational Attainment, 2013-2015

\begin{tabular}{lccc}
\hline & High school or less & Some college & College or more \\
\hline White & 2.38 & 1.81 & 1.65 \\
Black & 2.55 & 2.20 & 1.55 \\
Hispanic & 2.82 & 1.96 & 1.85 \\
Other & 2.49 & 1.91 & 1.26 \\
\hline
\end{tabular}

Source: National Survey of Family Growth (2013-2015). 
Table 3. Percentage Distribution of Religious Affiliation, Women Ages 15-45, 2013-2015

\begin{tabular}{lc}
\hline Religious affiliation & Percent \\
\hline Fundamentalist & $4.9 \%$ \\
Catholic & 21.9 \\
Mainline Protestant & 42.4 \\
Other religion & 7.8 \\
No religion & 23.2 \\
\hline
\end{tabular}

Source: National Survey of Family Growth (2013-2015).

Table 4. Percentage of the Population with No Religion, Various Measures

\begin{tabular}{ll}
\hline U.S. Religion Census: Religious Congregations and Membership Study & \\
\hline Religious congregation membership data divided by total state population & $51.1 \%$ \\
\hline National Survey of Family Growth ${ }^{\text {I }}$ & \\
\hline Self-reports no religion & $23.2 \%$ \\
Self-reports no religion + reports religious affiliation but never attends services & 33.2 \\
Self-reports no religion + reports religious affiliation but attends less than twice a year & 43.8 \\
\hline
\end{tabular}

${ }^{1}$ Respondents are females between the ages of 15 and 45. Religious affiliation was identified through the questions: 1) What religion are you now, if any?; and 2) About how often do you attend religious services? Source: Authors' calculations from National Survey of Family Growth (2013-2015); and U.S. Religion Census: Religious Congregations and Membership Study (2010).

Table 5. Structural Characteristics, 2001 and 2016

\begin{tabular}{lcc}
\hline & 2001 & 2016 \\
\hline Proportions & $13.1 \%$ & $17.2 \%$ \\
Hispanic & 4.9 & 5.9 \\
$\quad$ Foreign-born & 8.2 & 11.3 \\
$\quad$ Native-born & 12.4 & 12.4 \\
Black & 28.1 & 38.9 \\
College or more & 49.9 & 51.1 \\
No religion & & \\
Cost Ratios & 67.0 & 71.1 \\
Ratio of female to male wage & 3.5 & 4.3 \\
Ratio of child cost to income &
\end{tabular}

Note: Hispanic and Black shares are calculated as a percentage of women ages 15-49. College or more shares are calculated as a percentage of women ages 25-49. No religion shares are as a percent of the state population. Source: Authors' calculations from Census Bureau, American Community Survey (2001-2003 and 2014-2016); U.S. Religion Census, Religious Congregations and Membership Study (2000 and 2010); Zillow Home Values (20012003 and 2014-2016; U.S. Department of Education, National Center for Education Statistics, Digest of Education Statistics (2001-2003 and 2014-2016); and Childcare Aware, National Data System for Child Care (2014-2016); and Urban Institute, National Survey of American Families (1999-2002). 
Figure 1. General Fertility Rate (Births per Thousand Women Ages 15-49), 1915-2017

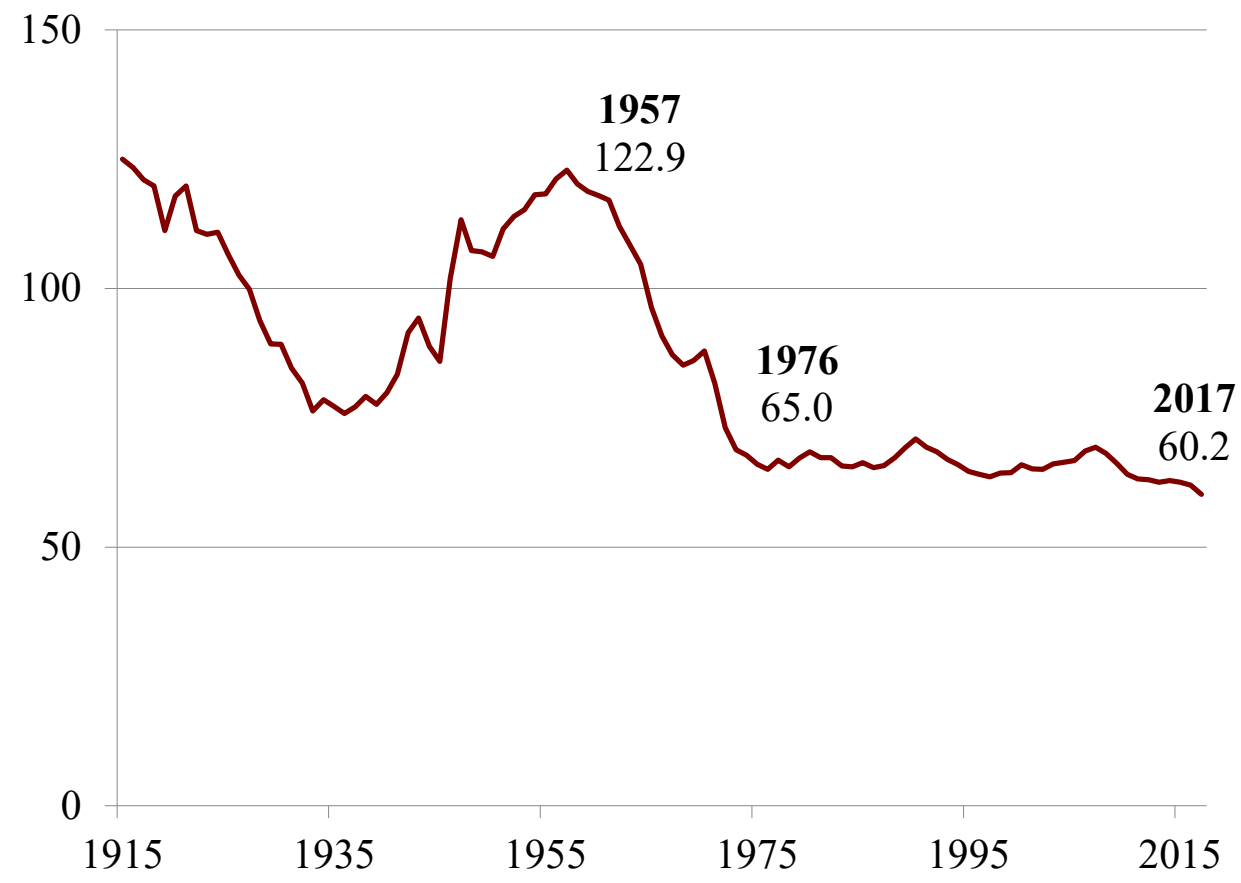

Sources: Centers for Disease Control and Prevention, U.S. National Vital Statistics Reports (2016-17); Max Planck Institute for Demographic Research and Vienna Institute of Demography, Human Fertility Database (1915-2015).

Figure 2. Births per Thousand Women by Age, 2001, 2009, 2017

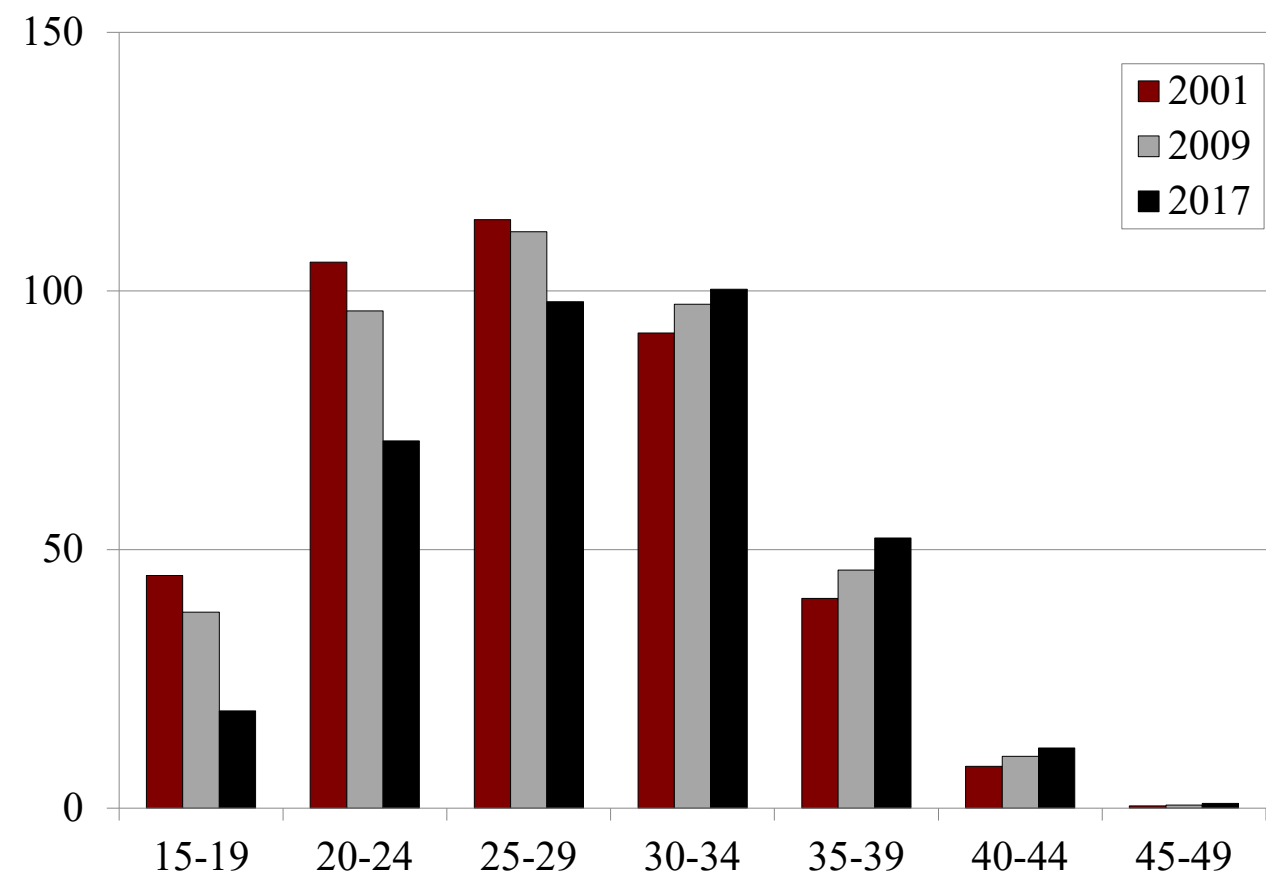

Sources: Centers for Disease Control and Prevention, National Center for Health Statistics, Vital Statistics Natality Birth Data (2001, 2009, and 2017). 
Figure 3. Total Fertility Rate (Hypothetical Lifetime Births per Woman) 1915-2017

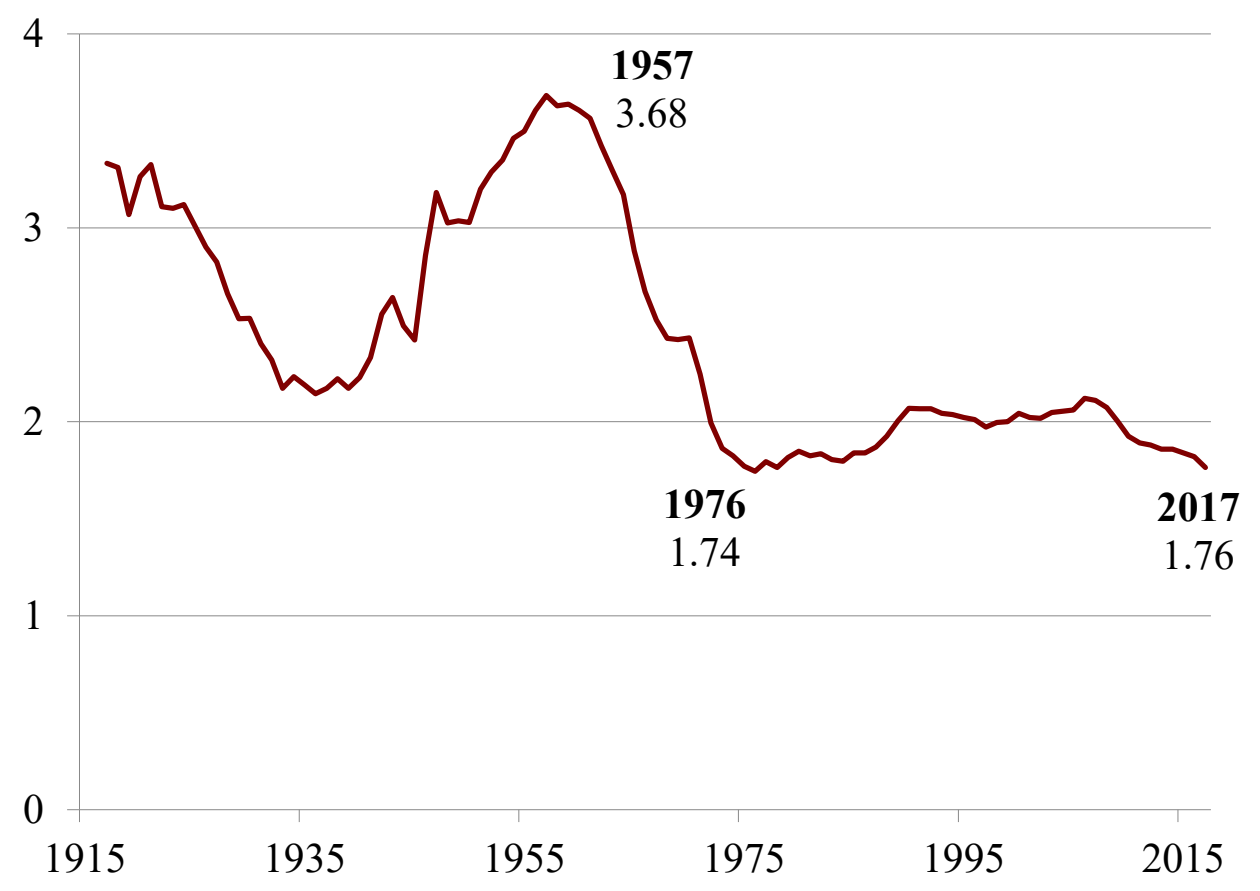

Sources: Centers for Disease Control and Prevention, U.S. National Vital Statistics Reports (2016-2017); and Max Planck Institute for Demographic Research and Vienna Institute of Demography, Human Fertility Database (19152015).

Figure 4. Births per Thousand Women, by Age 1978 and 2017

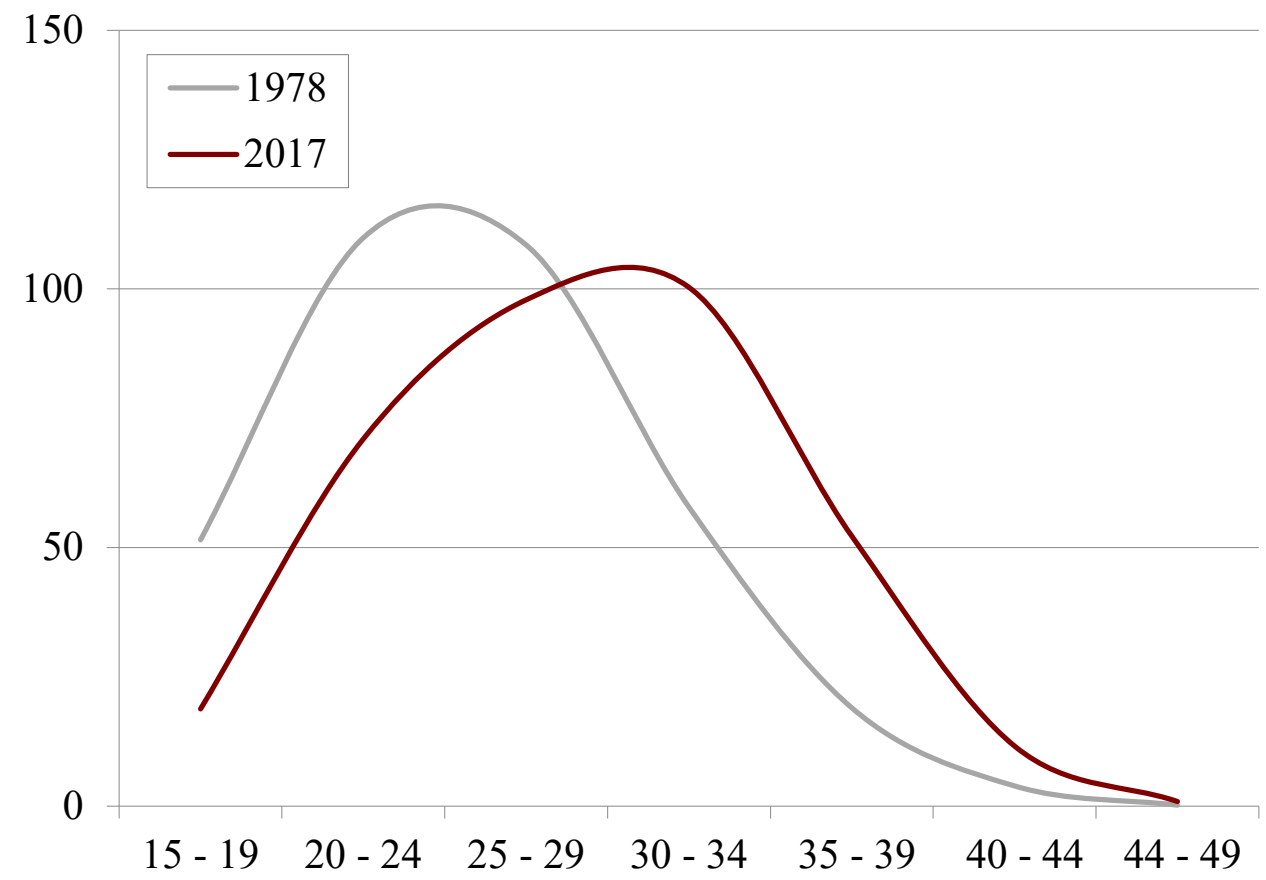

Sources: Centers for Disease Control and Prevention, National Center for Health Statistics, Vital Statistics Natality Birth Data (1978 and 2017). 
Figure 5. Cumulative Percentage of Annual Births by Parity, 1940-2016

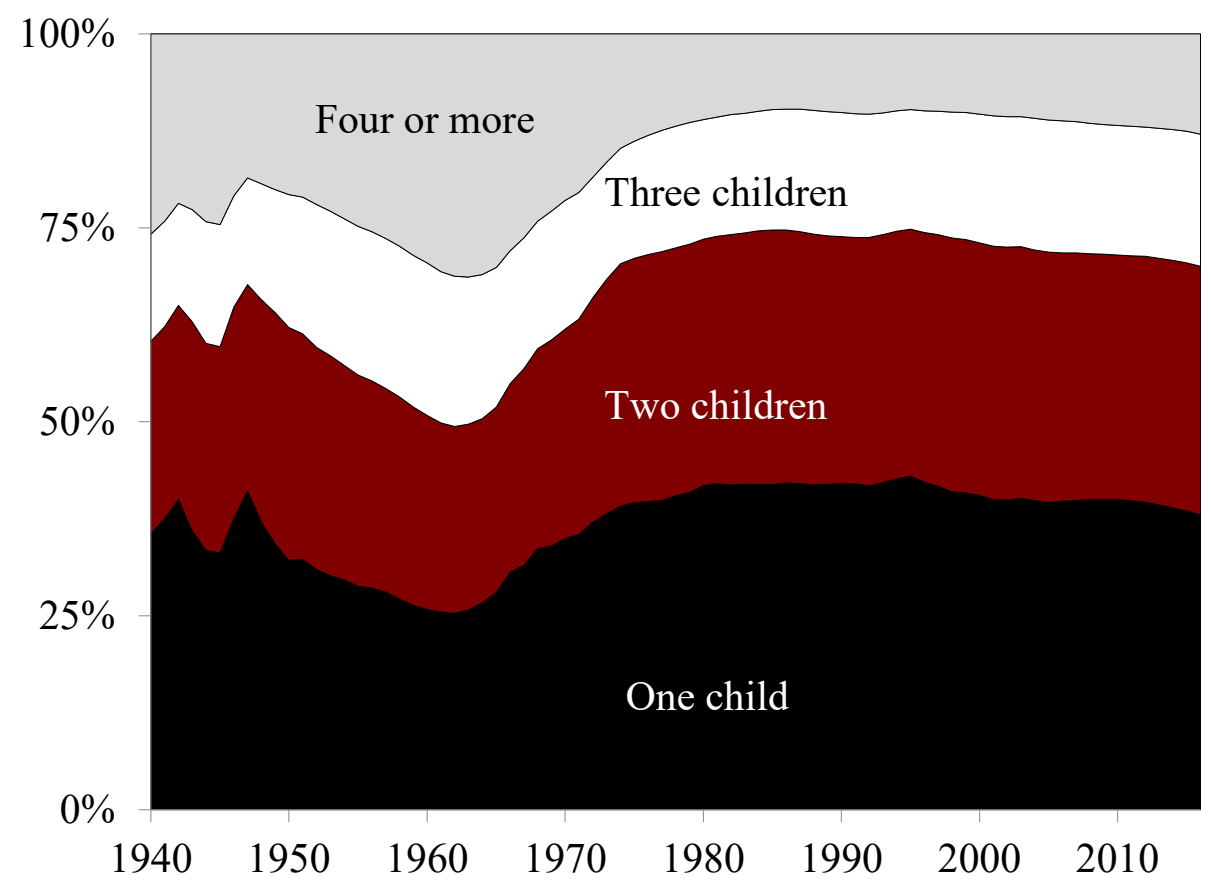

Sources: Max Planck Institute for Demographic Research and Vienna Institute of Demography, Human Fertility Database (1940-2015); and Centers for Disease Control and Prevention, U.S. National Vital Statistics Report (2016).

Figure 6. Total Fertility (Period) Rate and Completed Fertility (Cohort) Rate, 1940-2016

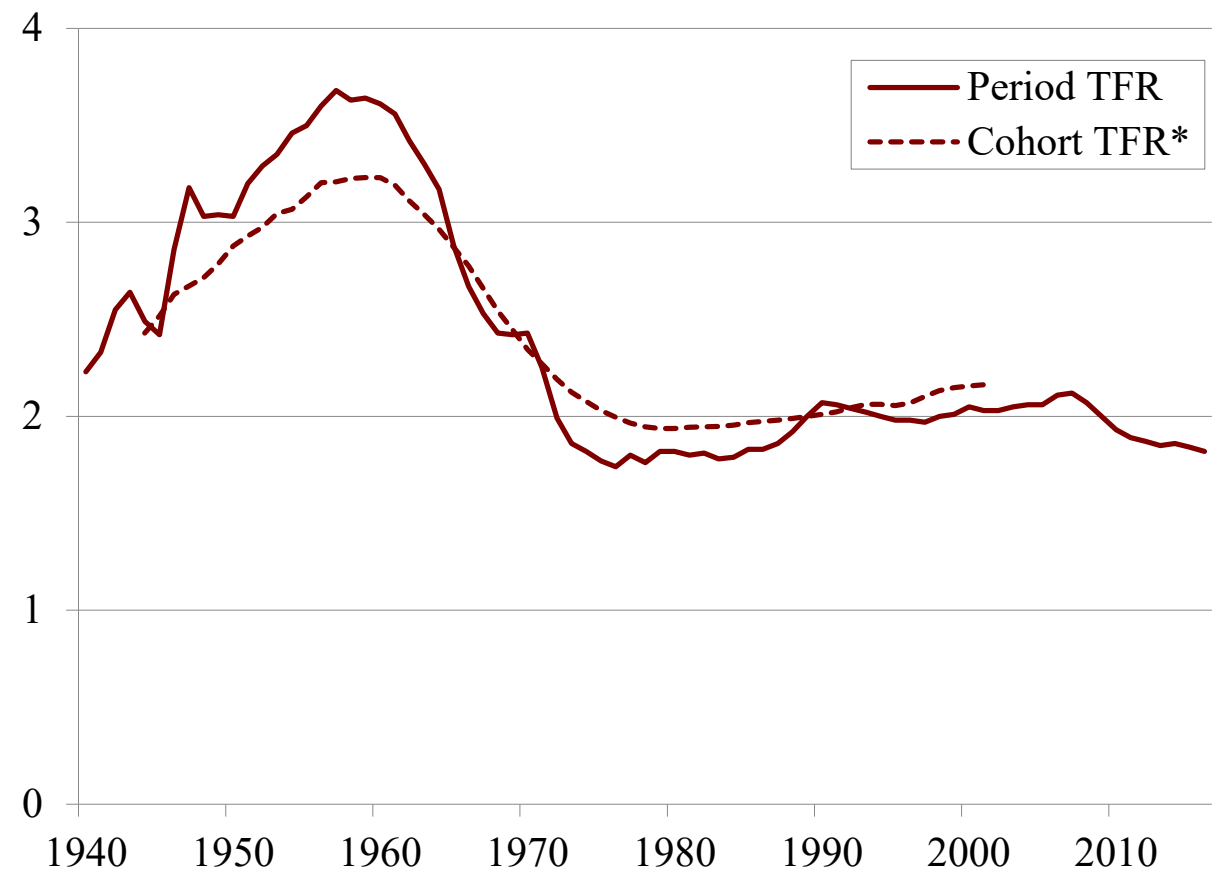

Note: Asterisk (*) for cohort born $t$-26, using the adjustment formula used by Preston and Hartnett (2009). Source: Max Planck Institute for Demographic Research and Vienna Institute of Demography, Human Fertility Database. 
Figure 7. Mean Age for First Birth and for All Births, 1940-2016

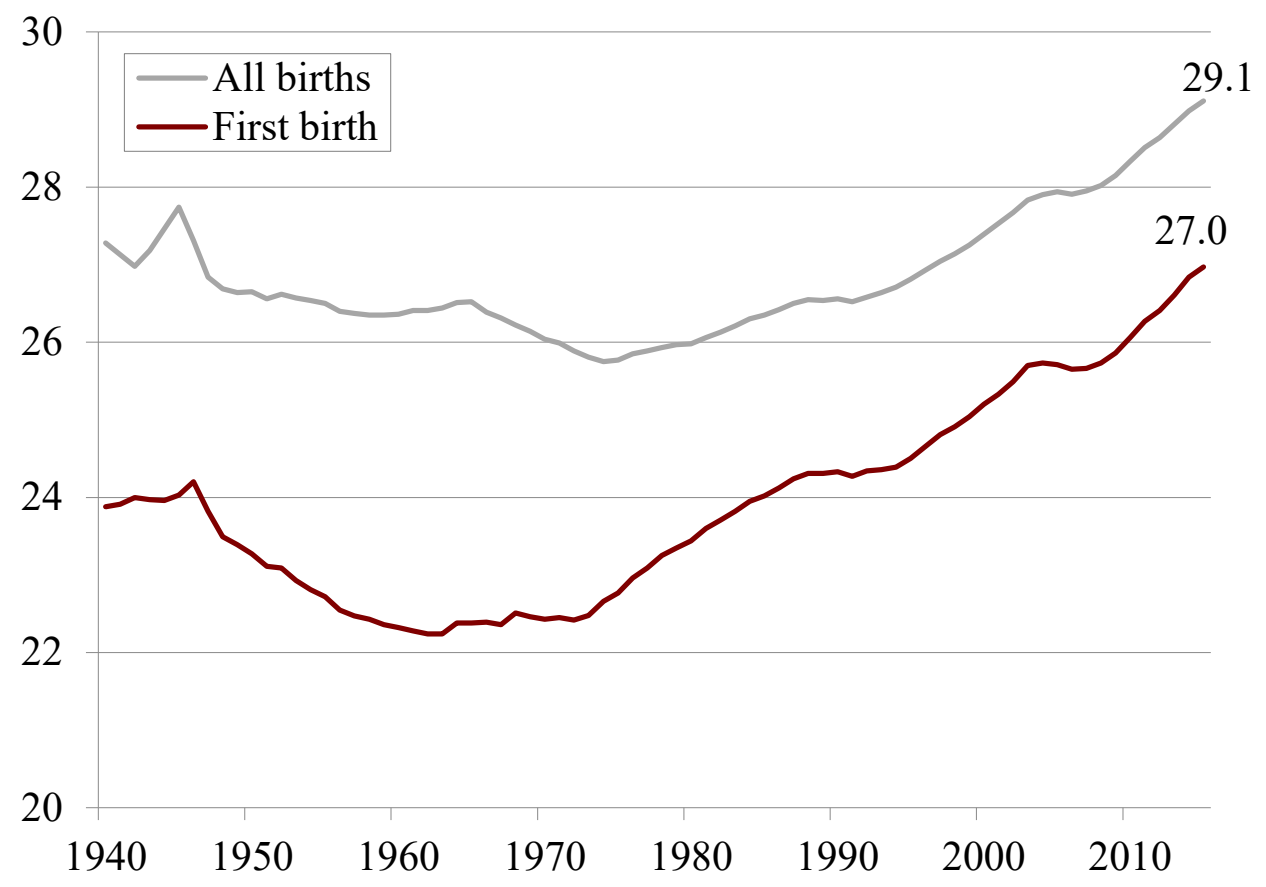

Sources: Max Planck Institute for Demographic Research and Vienna Institute of Demography, Human Fertility Database (1940-2015); and Centers for Disease Control and Prevention, U.S. National Vital Statistics Report (2016).

Figure 8. Total Births Expected among Women Aged 20-24, Various Years

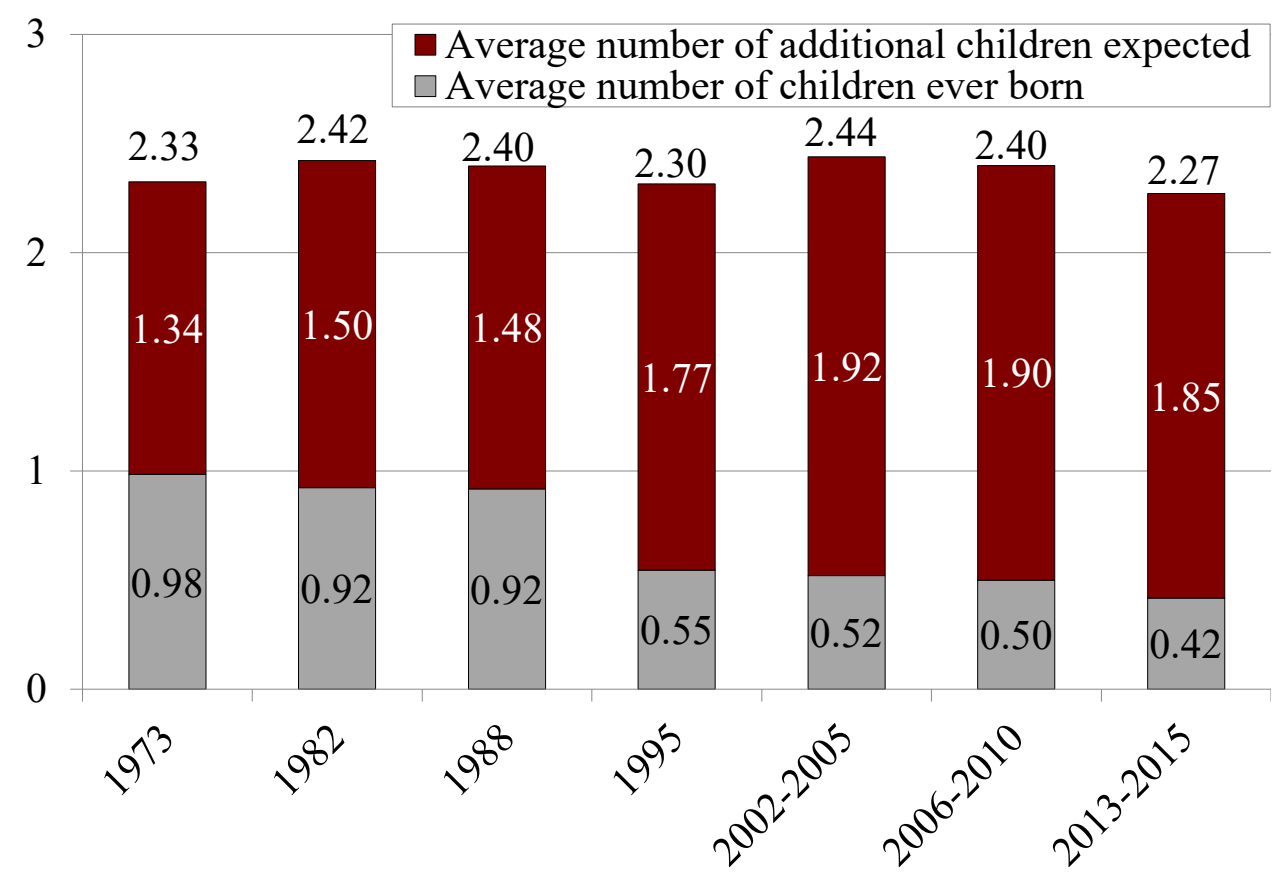

Note: Prior to 2002, only married women were asked about birth expectations in the National Survey of Family Growth.

Sources: Centers for Disease Control and Prevention, National Survey of Family Growth (NSFG), 2002, 2006-2010, 2011-2013, and 2013-2015. 
Figure 9. Expected vs Actual Fertility, Various Cohorts

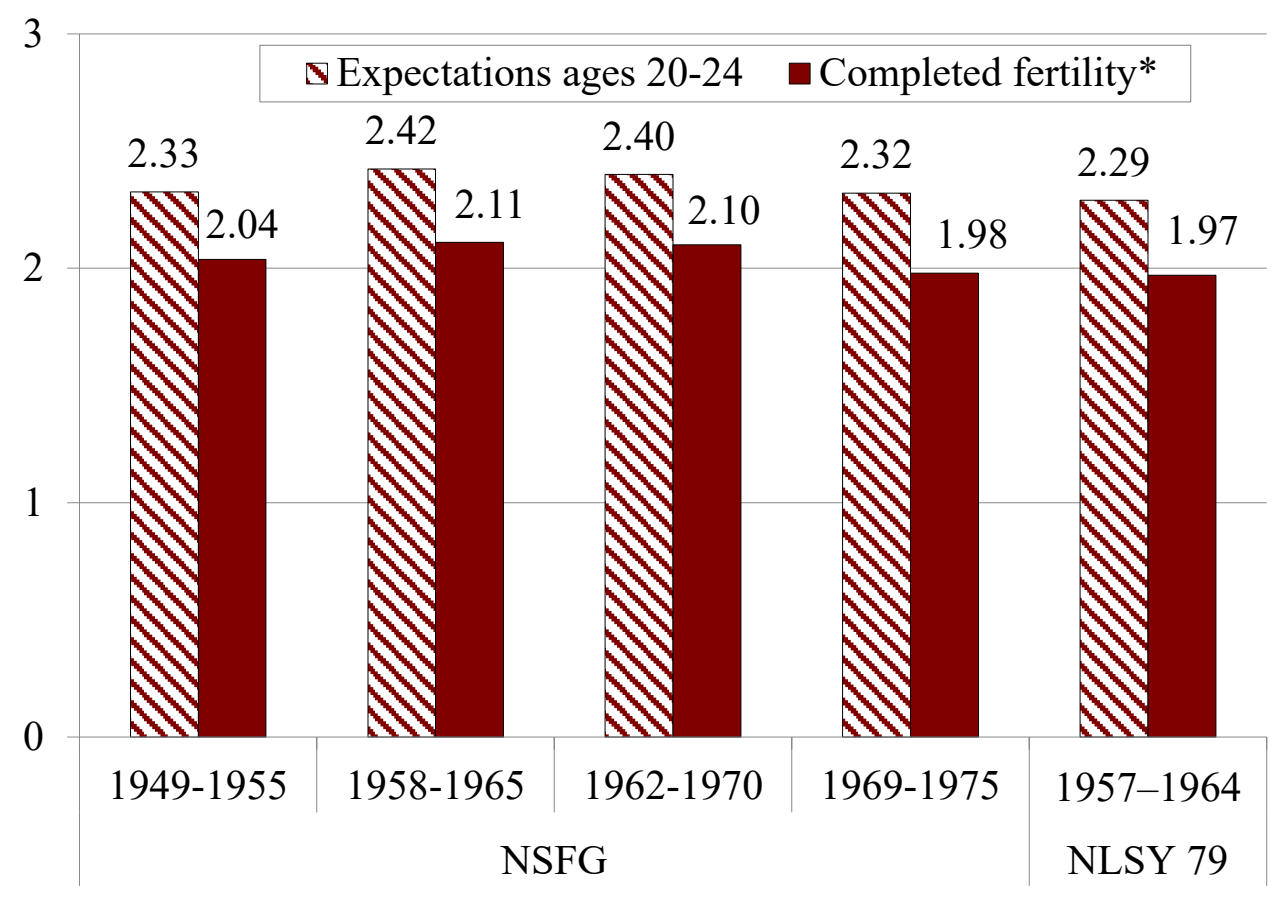

* The completed fertility measure represents women ages 40-45 in the NSFG and 45-49 in the NLSY79. Note: Prior to 2002, only married women were asked about birth expectations in the National Survey of Family Growth.

Sources: NSFG 1973, 1982, 1995, 2002-2005, 2006-2010, 2013-2015; and NLSY79 (1979-2014). 
Figure 10. Relationship between the Change in TFR and the Change in the Unemployment Rate during the Great Recession and Subsequent Expansion, by State

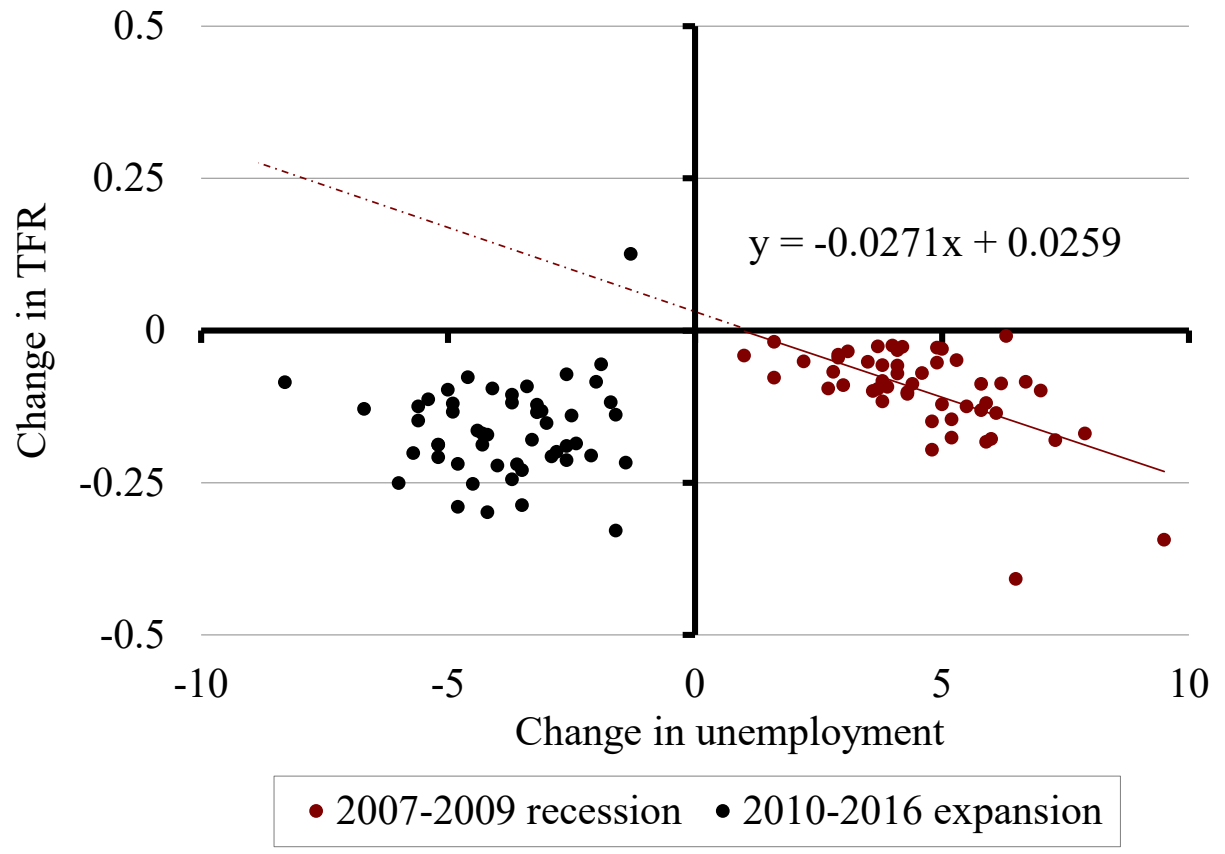

Note: Recession years are defined as the years between the peak and trough of real GDP for each state.

Sources: Authors' calculations from Bureau of Labor Statistics (2005-2016); and Centers for Disease Control and Prevention, National Center for Health Statistics, Vital Statistics Natality Birth Data (2005-2016). 
Figure 11. Pattern of Change in TFR across States during Expansions and Recessions, 19762016

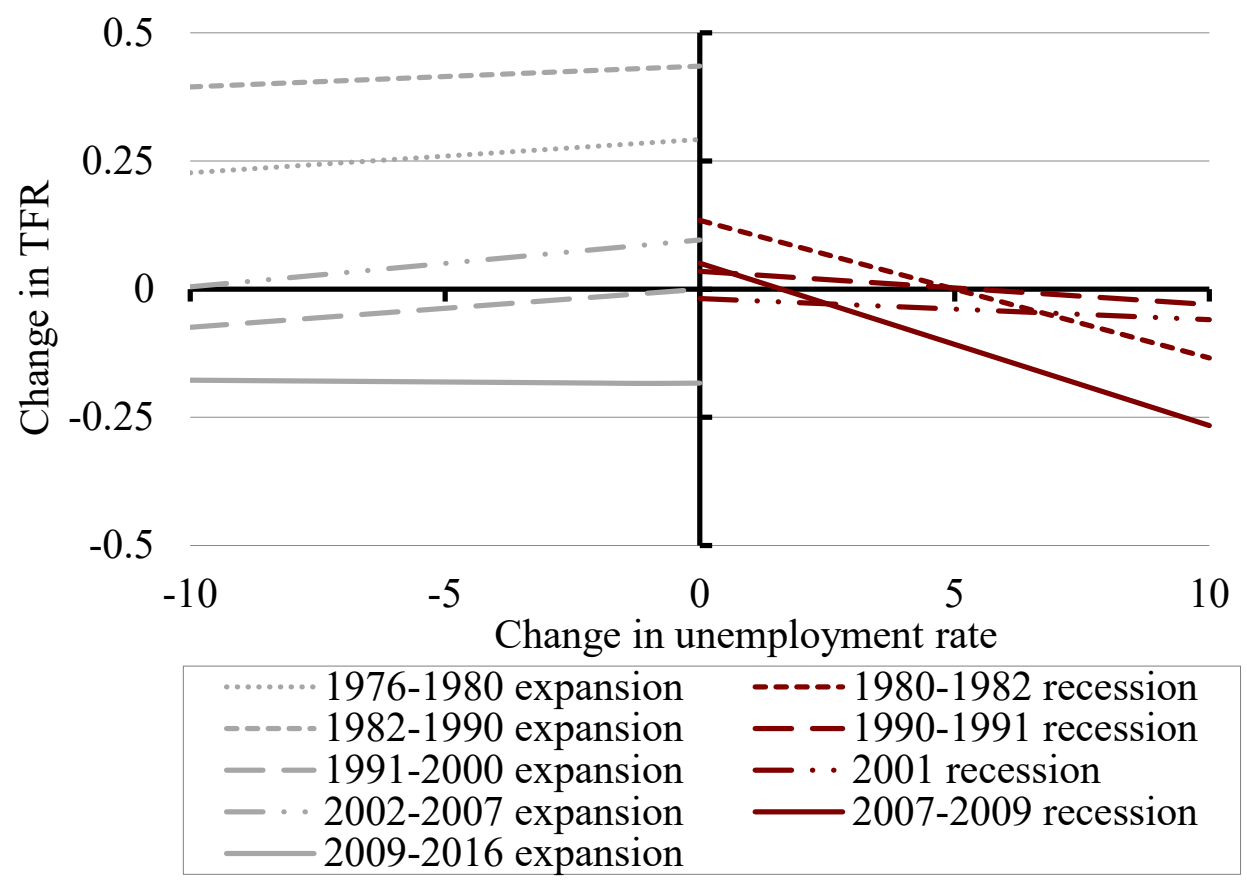

Note: Recession years are defined as the years between the peak and trough of real GDP for each state.

Sources: Authors' calculations from Bureau of Labor Statistics (1976-2016); and Centers for Disease Control and Prevention, National Center for Health Statistics, Vital Statistics Natality Birth Data (1976-2016). 
Figure 12. Total Fertility Rate and Tempo-Adjusted Fertility Rate, 1976-2016

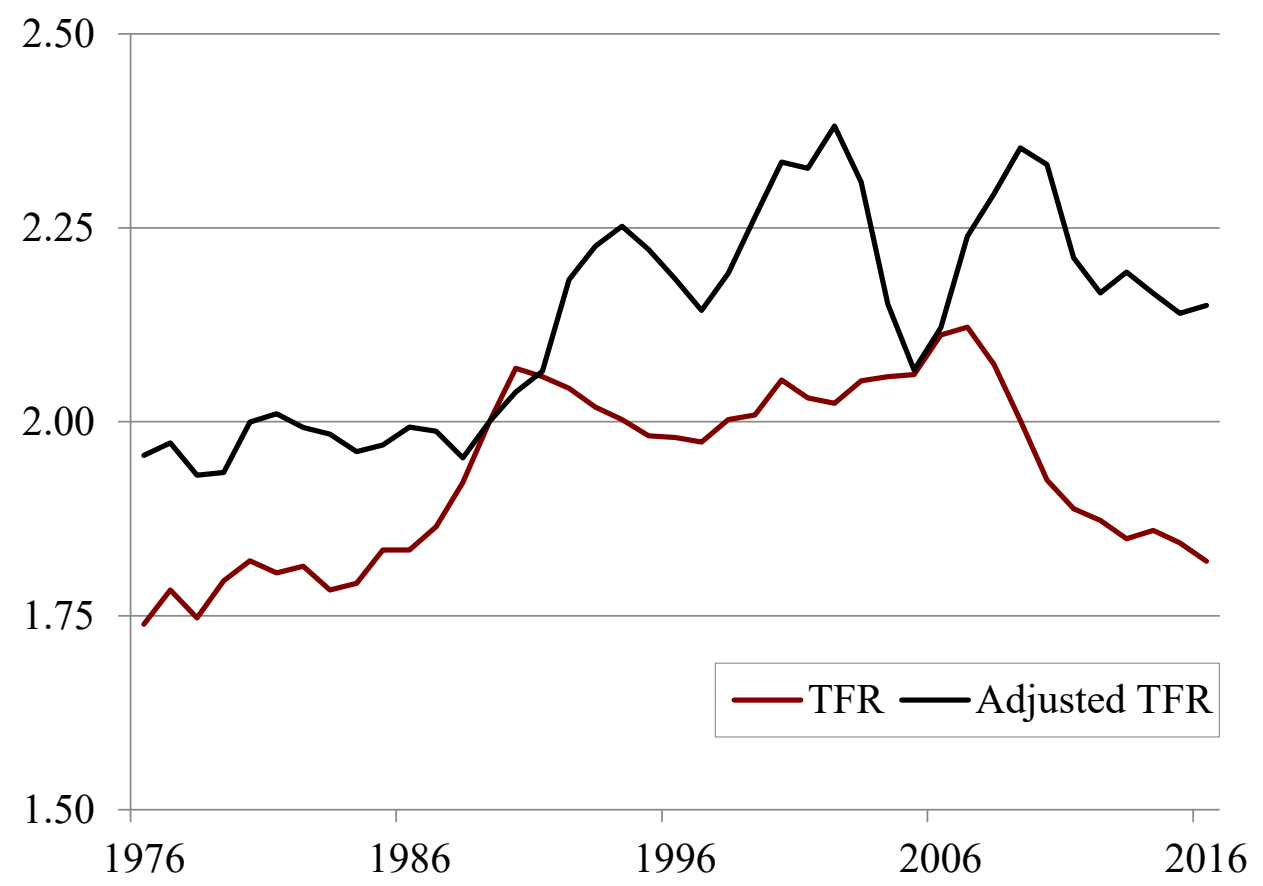

Sources: Authors' calculations using Max Planck Institute for Demographic Research and Vienna Institute of Demography, Human Fertility Database (1976-2015); and Centers for Disease Control and Prevention, U.S. National Vital Statistics Report (2016).

Figure 13. Age-specific Fertility Rates, 2001-2017

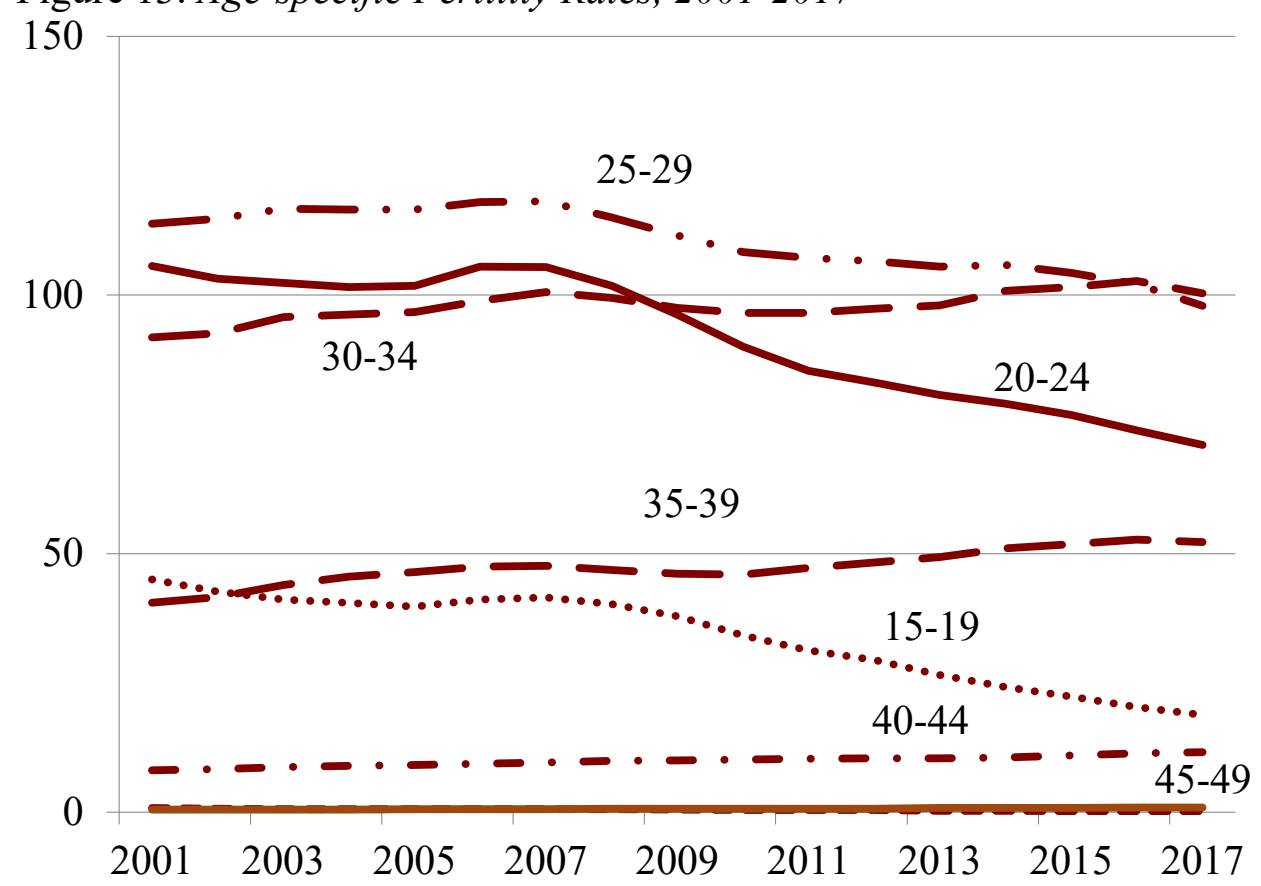

Source: Centers for Disease Control and Prevention, National Center for Health Statistics, Vital Statistics Natality Birth Data (2001-2017). 
Figure 14. Period Total Fertility Rate and Completed Fertility Rate, 1976-2016

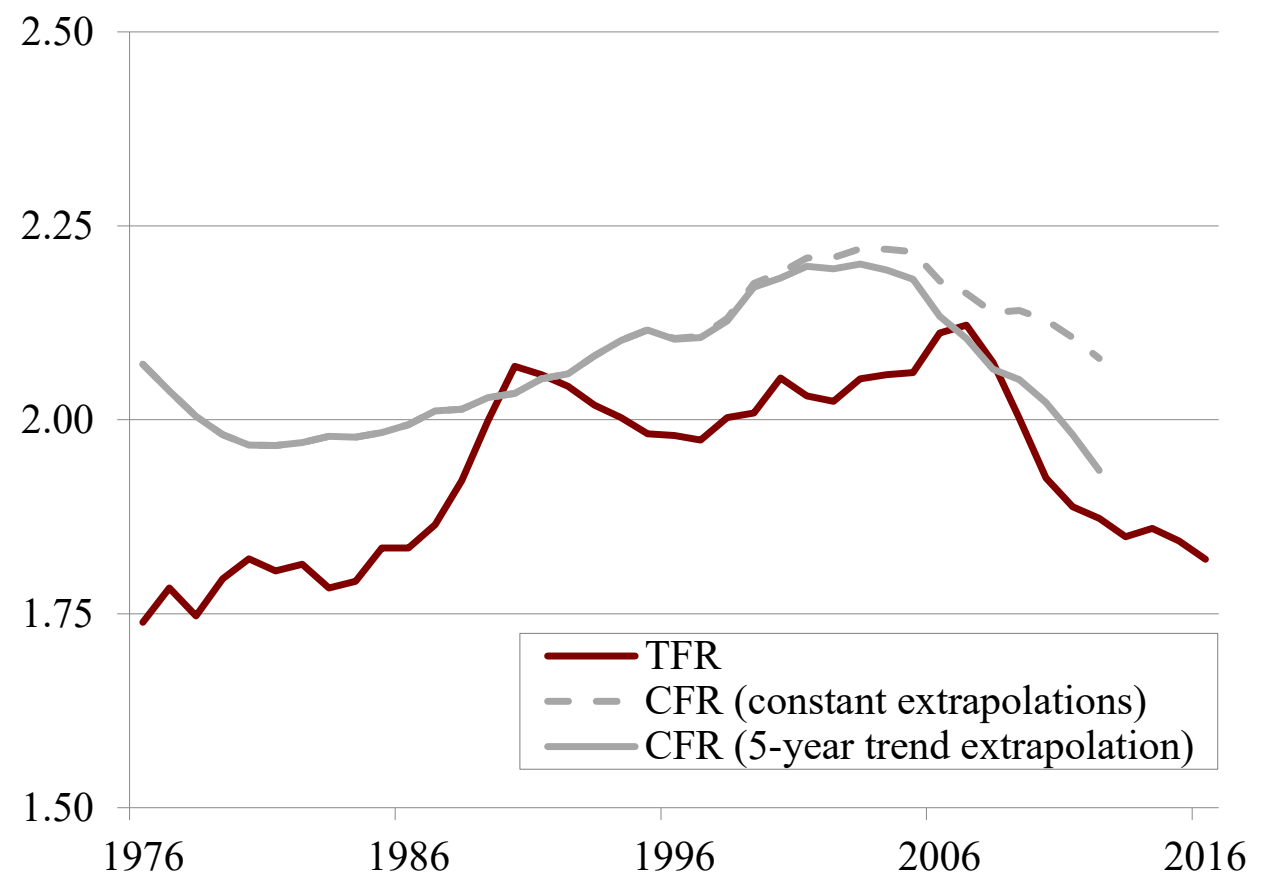

Note: The completed fertility rate is for cohort born $t-27$, the average age of childbirth.

Sources: Authors' calculations using Max Planck Institute for Demographic Research and Vienna Institute of Demography, Human Fertility Database (1976-2015); and Centers for Disease Control and Prevention, U.S. National Vital Statistics Report (2016). 
Figure 15. Total Fertility Rate, By Ethnicity, 1976-2016

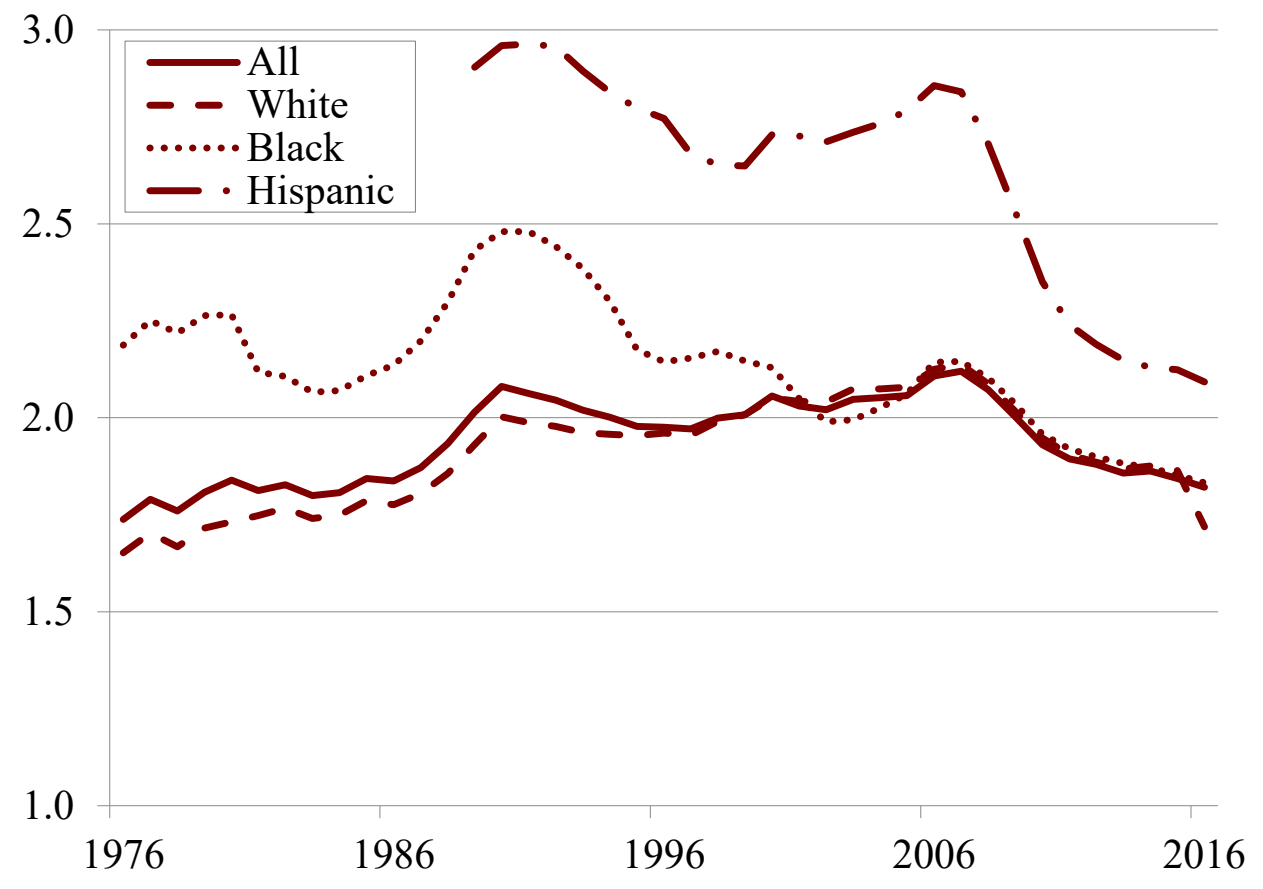

Source: Authors' calculations from Centers for Disease Control and Prevention, U.S. National Vital Statistics Reports (1976-2016) 
Figure 16. Total Fertility Rates in Select Countries, 2001 and 2015

a. 2001

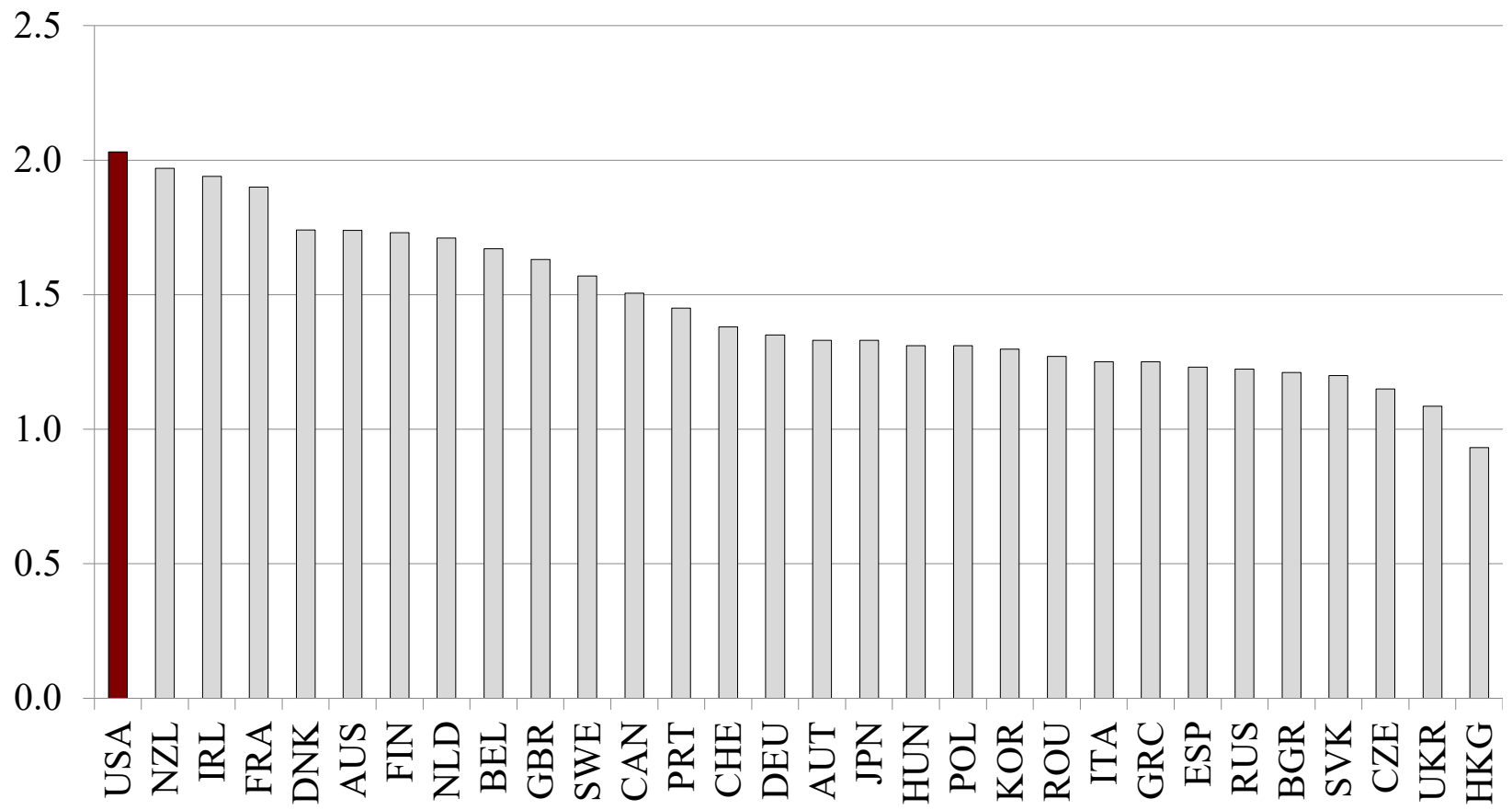

b. 2015

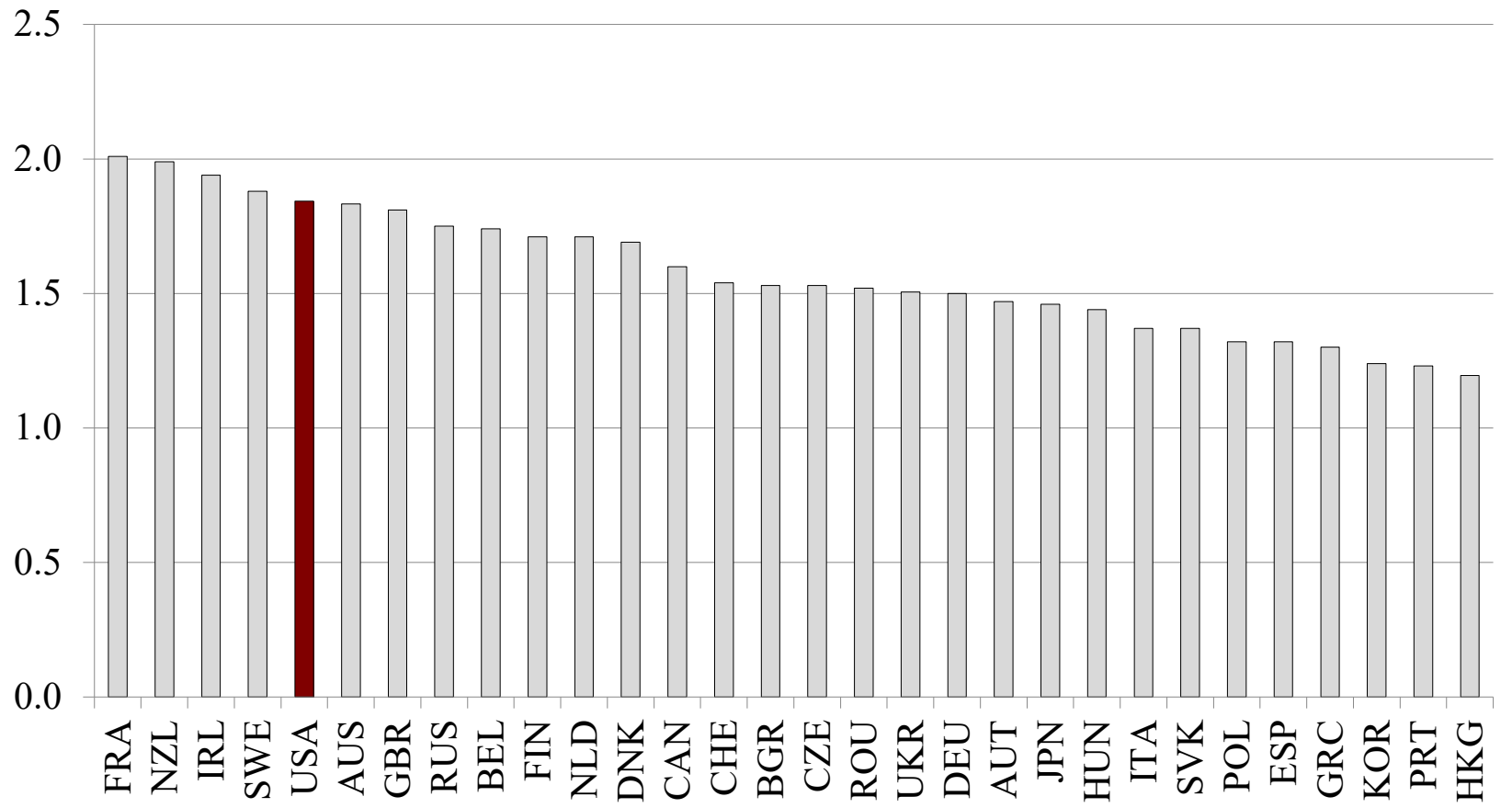

Source: OECD (2016). 
Figure 17. Mean Number of Children Ever Born to Women Ages 40-44, by Educational Attainment, 1976-2016

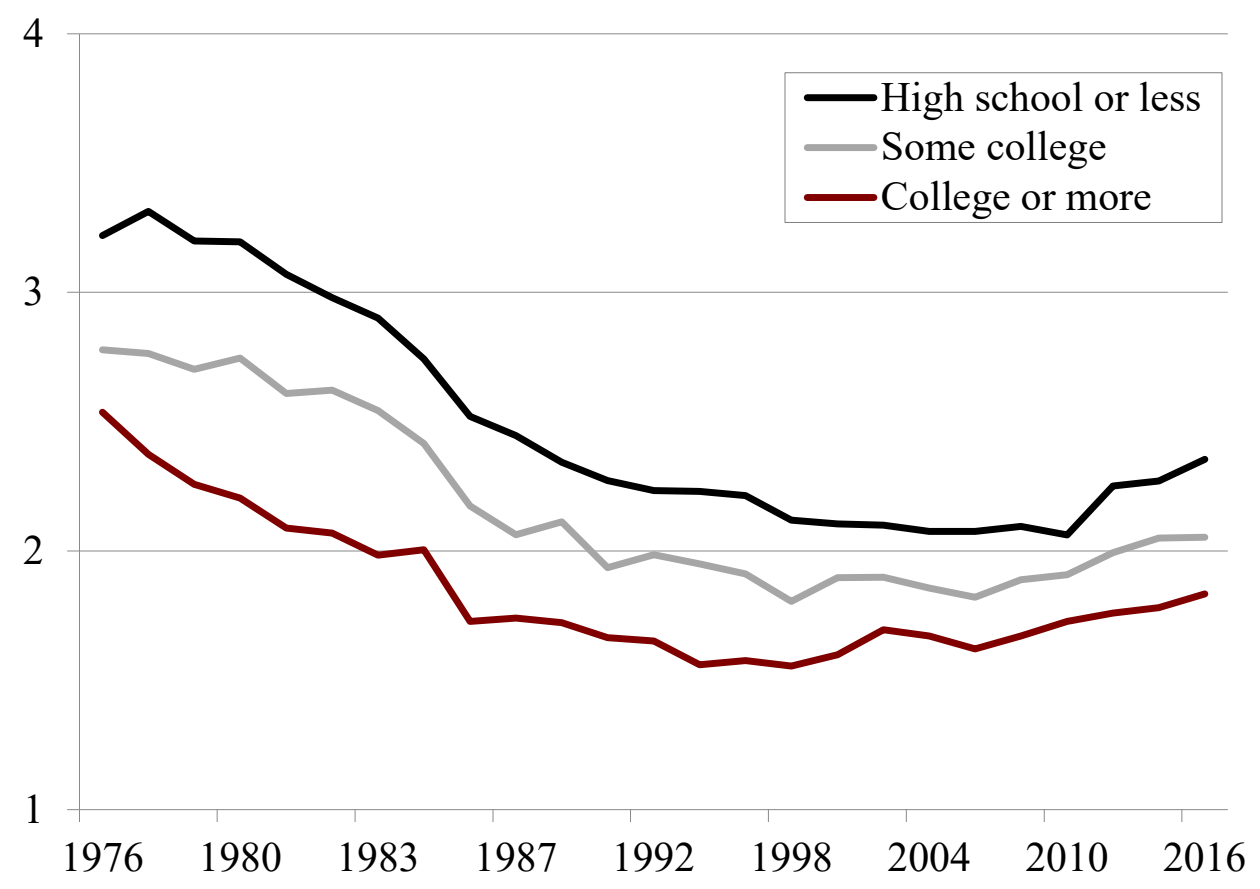

Source: Authors' calculations from Current Population Survey, Fertility Supplement (1976-2016).

Figure 18. Educational Attainment for Women, Age 25-49, 1979-2016

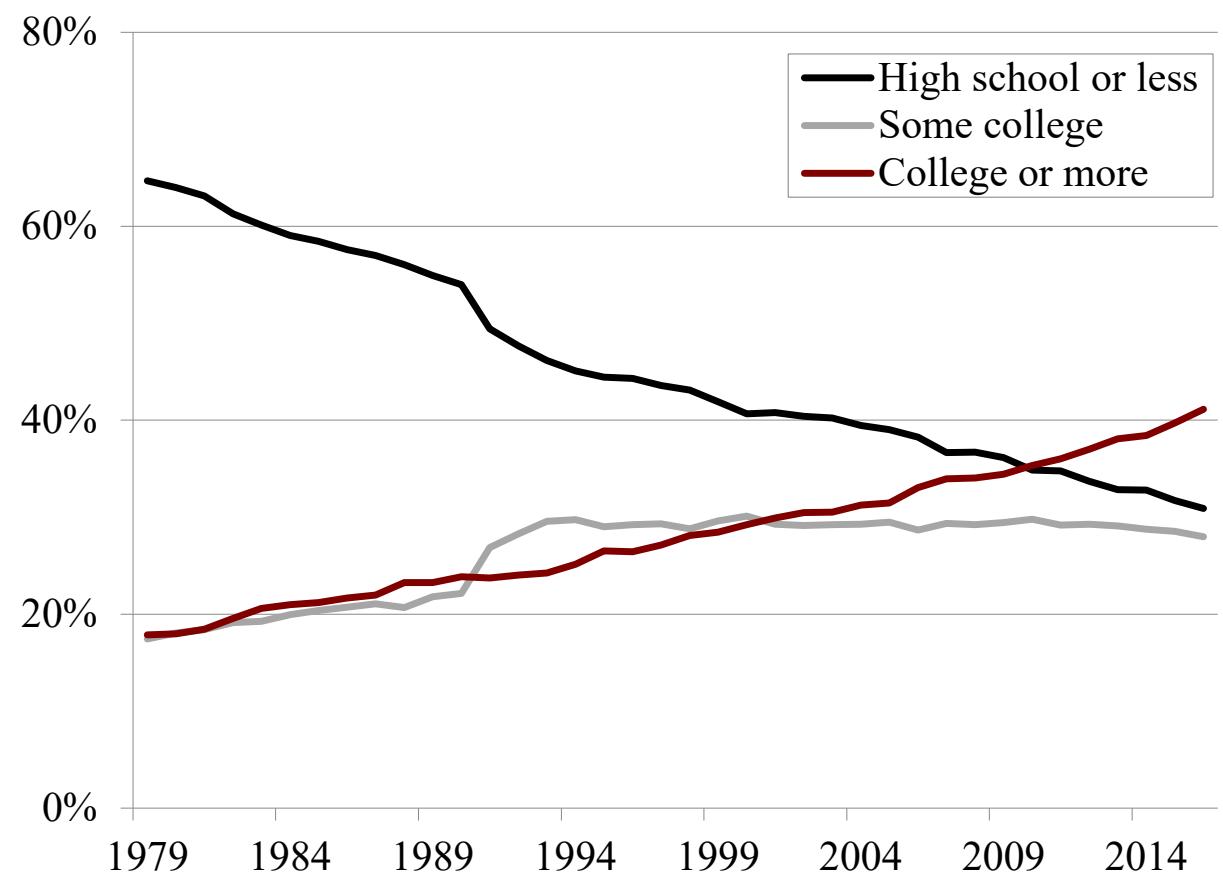

Source: Authors' calculations from Current Population Survey, ASEC (1980-2017). 
Figure 19. Total Births and Expected Births for Women 25-30, By Education, 2013-2015

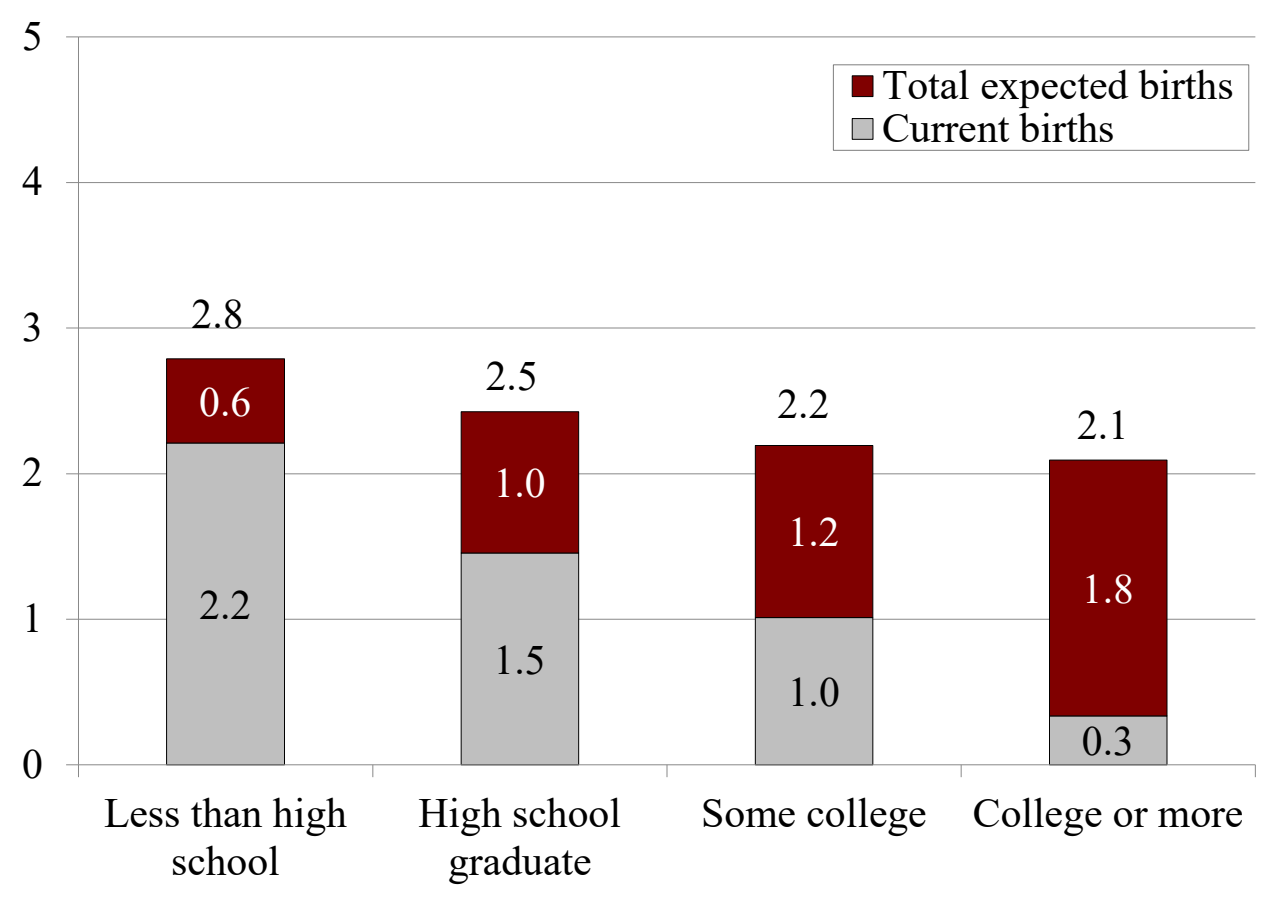

Source: National Survey of Family Growth (2013-2015).

Figure 20. Number of Children Ever Born for Women Ages 40-45, by Religious Affiliation, 20132015

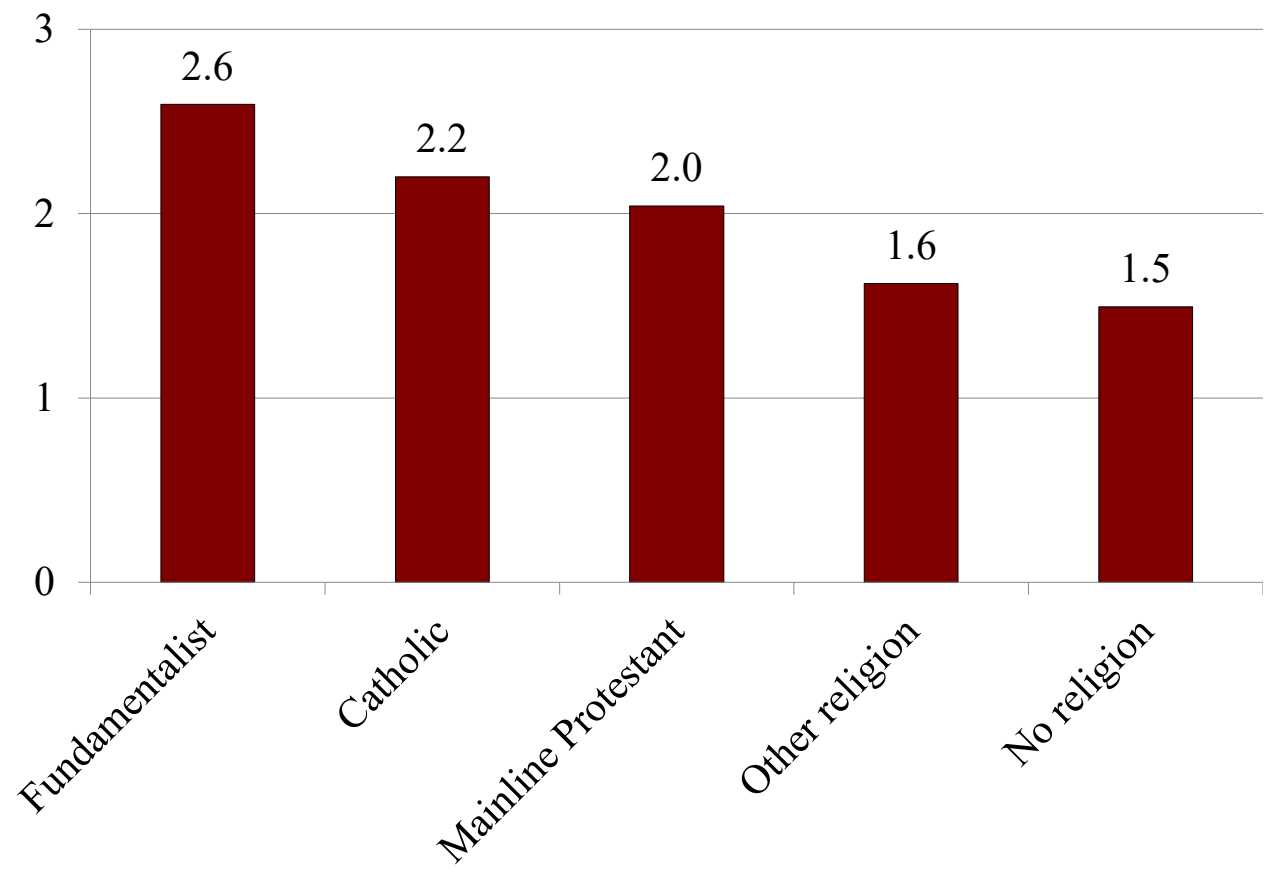

Source: National Survey of Family Growth (2013-2015). 
Figure 21. Ratio of Female to Male Wages by State, 2001

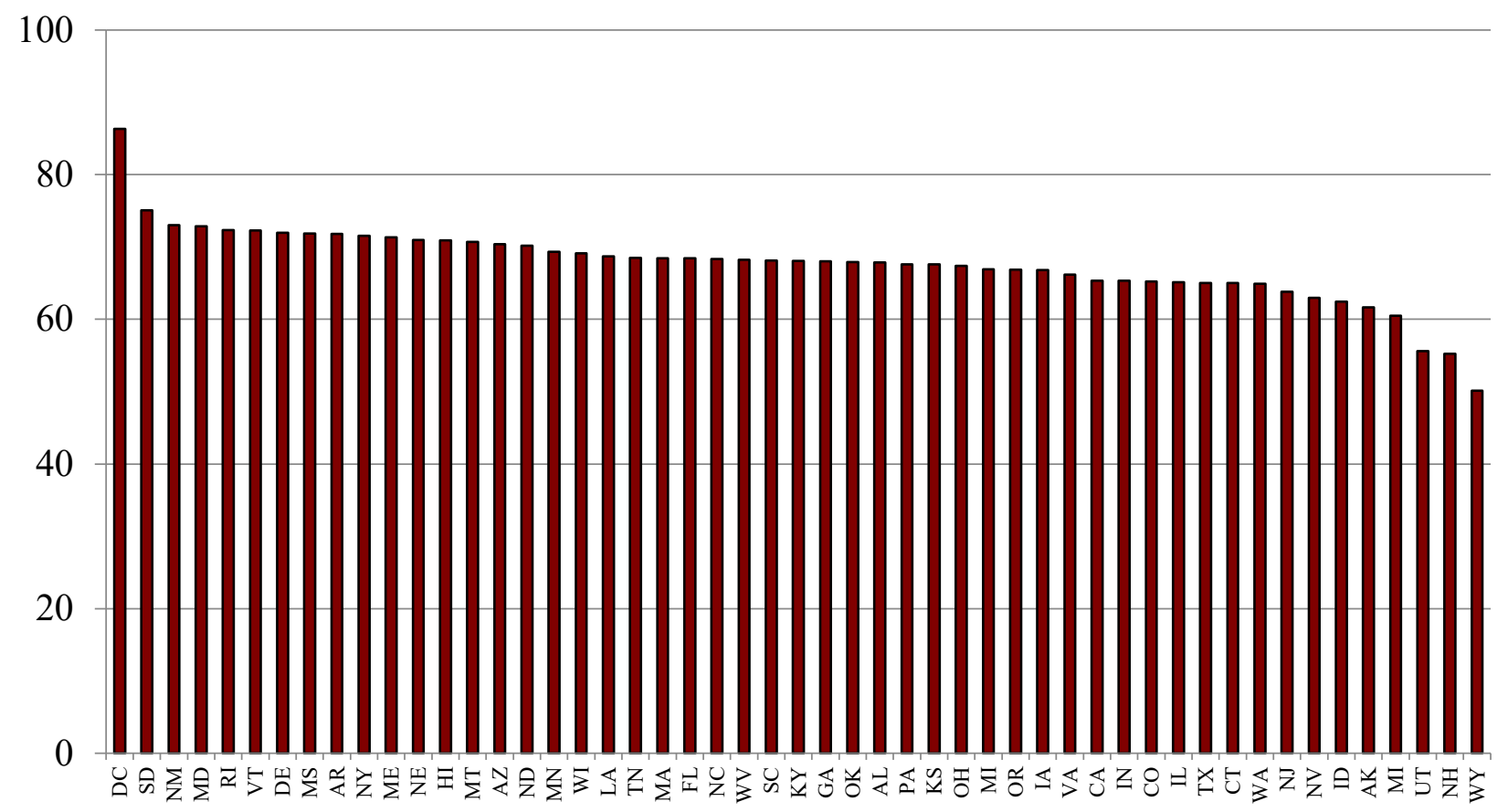

Source: Authors' calculations from Census Bureau, American Community Survey (2001).

Figure 22. Ratio of Child Costs to Income by State, 2001

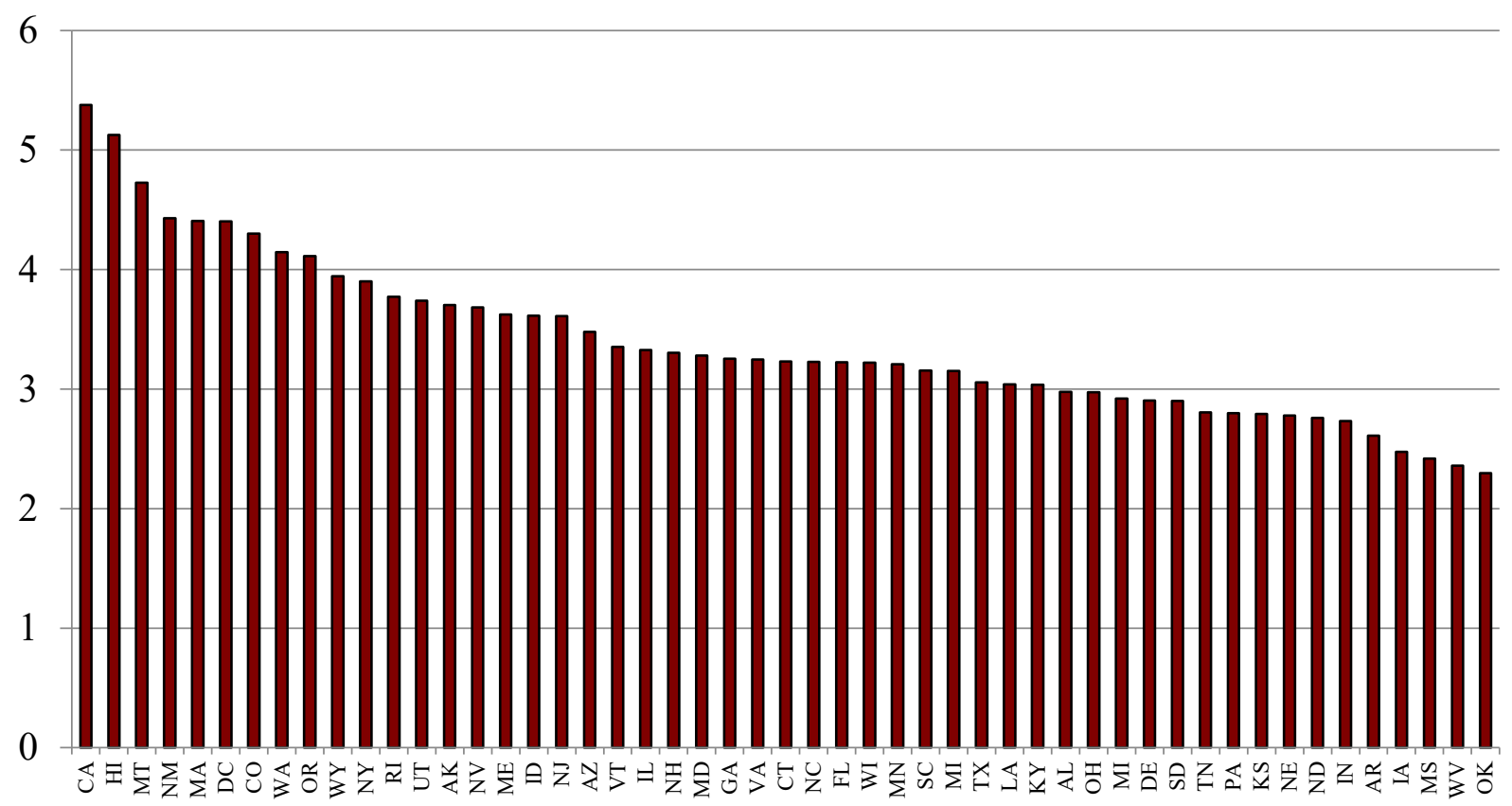

Sources: Authors' calculations from Census Bureau, American Community Survey (2001), Zillow Home Values (2001-2003 and 2014-2016); U.S. Department of Education, National Center for Education Statistics, Digest of Education Statistics (2001-2003 and 2014-2016); Childcare Aware, National Data System for Child Care (20142016); and Urban Institute, National Survey of American Families (1999-2002). 
Figure 23. Regression Results of TFR on Select State-level Characteristics for 2001-2003 and 2014-2016

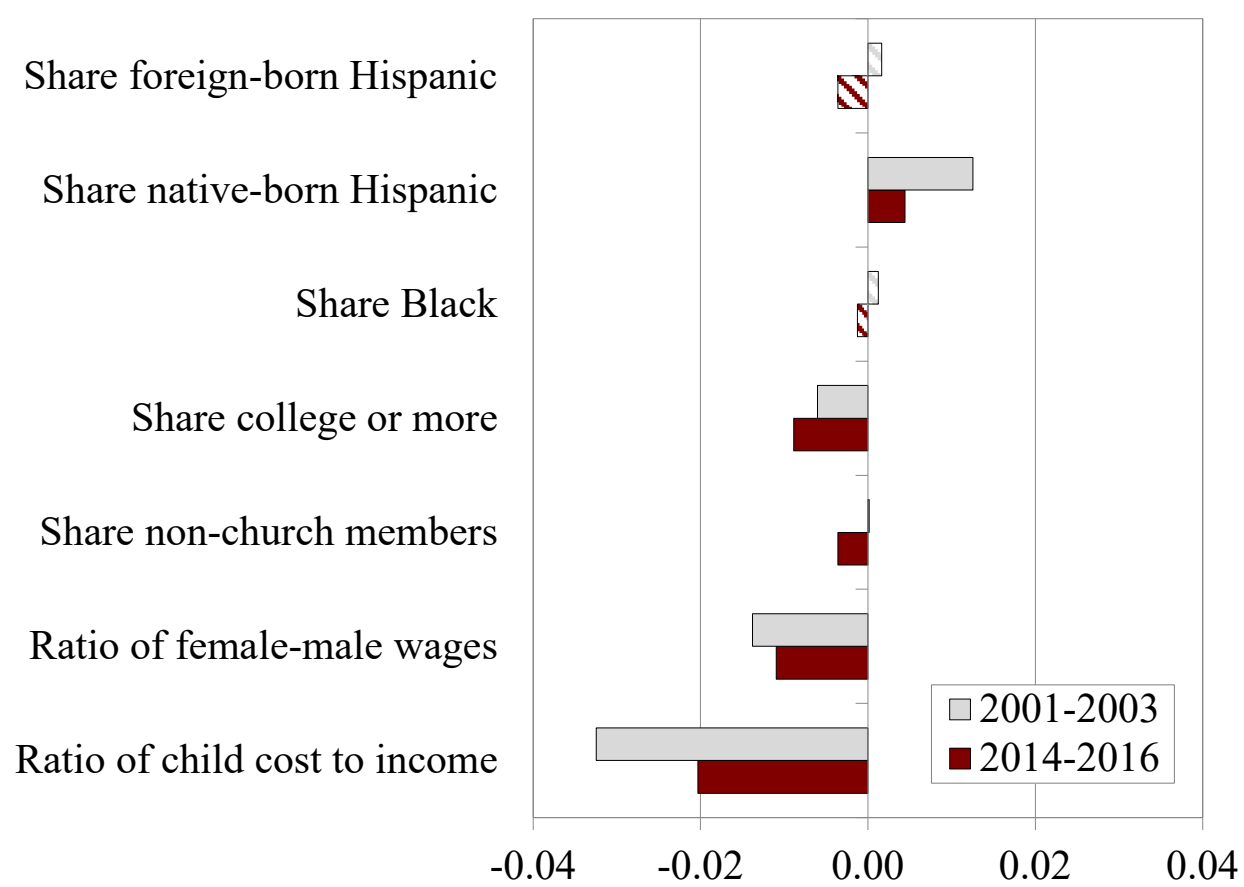

Note: Solid bars indicates statistically significant at the 5-percent or 1 percent level.

Sources: Authors' calculations from Census Bureau, American Community Survey (2001-2003 and 2014-2016); U.S. Religion Census, Religious Congregations and Membership Study (2000 and 2010); Zillow Home Values (20012003 and 2014-2016); U.S. Department of Education, National Center for Education Statistics, Digest of Education Statistics (2001-2003 and 2014-2016); Childcare Aware, National Data System for Child Care (2014-2016); and Urban Institute, National Survey of American Families (1999-2002). 
Figure 24. Results from Oaxaca-Blinder Decomposition

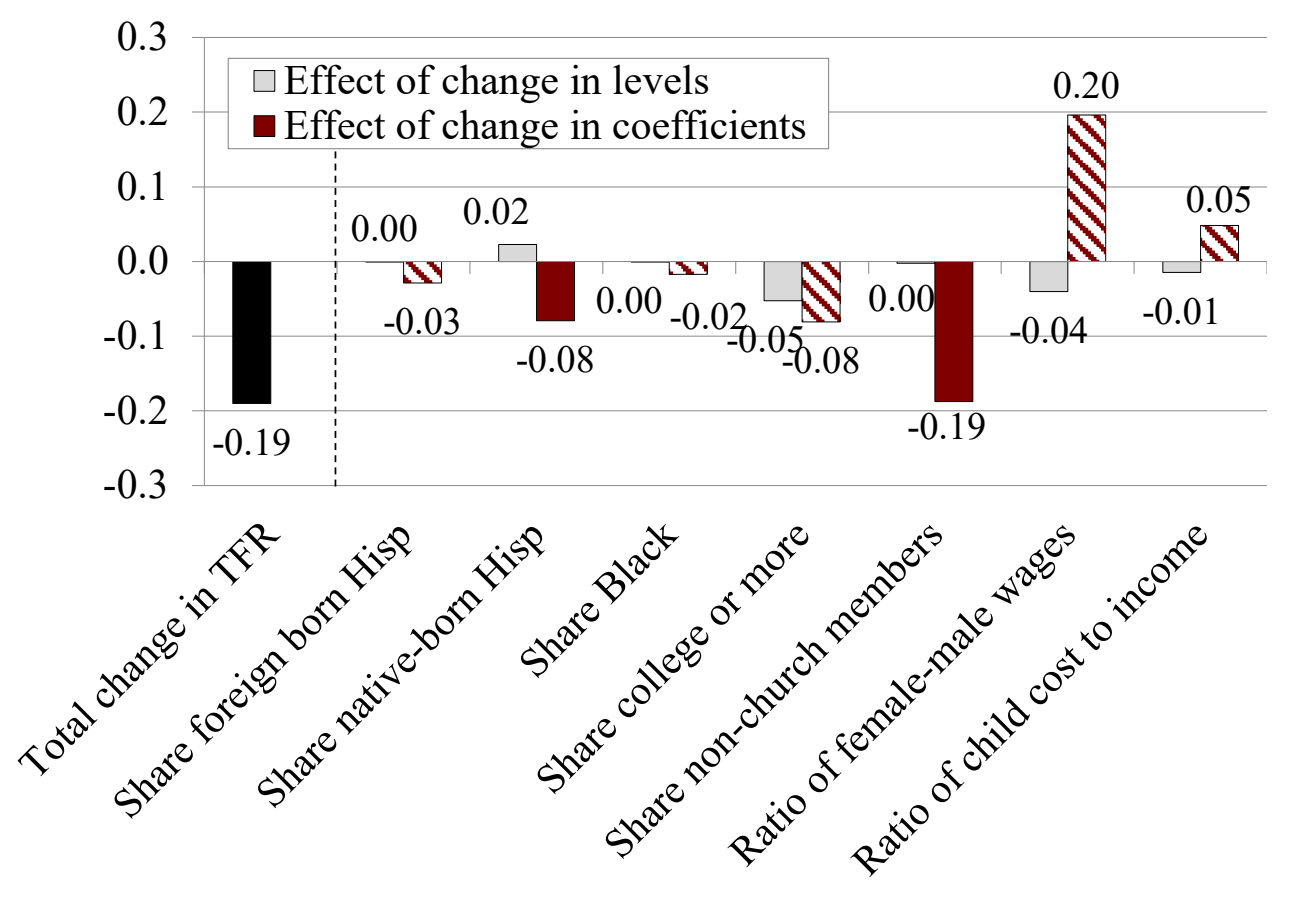

Note: Solid bars indicates statistically significant at the 5-percent or 1 percent level.

Sources: Authors' calculations from Census Bureau, American Community Survey (2001-2003 and 2014-2016); U.S. Religion Census, Religious Congregations and Membership Study (2000 and 2010); Zillow Home Values (20012003 and 2014-2016); U.S. Department of Education, National Center for Education Statistics, Digest of Education Statistics (2001-2003 and 2014-2016); Childcare Aware, National Data System for Child Care (2014-2016); and Urban Institute, National Survey of American Families (1999-2002). 


\section{Appendix}

Table A1. Effect of Business Cycles on the Change in TFR, 1976-2016

\begin{tabular}{|c|c|c|}
\hline & (1) & (2) \\
\hline & FE & $\mathrm{FE}+$ interaction \\
\hline \multirow[t]{2}{*}{ 1976-1980 expansion } & $0.231 * * *$ & $0.282 * * *$ \\
\hline & $(0.0703)$ & $(0.101)$ \\
\hline \multirow[t]{2}{*}{ 1980-1982 recession } & -0.0266 & 0.0747 \\
\hline & $(0.0445)$ & $(0.0773)$ \\
\hline \multirow[t]{2}{*}{ 1982-1990 expansion } & $0.353 * * *$ & $0.416 * *$ \\
\hline & $(0.135)$ & $(0.184)$ \\
\hline \multirow[t]{2}{*}{ 1990-1991 recession ${ }^{1}$} & -0.0289 & 0.00846 \\
\hline & $(0.0433)$ & $(0.0505)$ \\
\hline \multirow[t]{2}{*}{ 1991-2000 expansion } & -0.0696 & -0.0411 \\
\hline & $(0.0616)$ & $(0.0827)$ \\
\hline \multirow[t]{2}{*}{2001 recession } & $-0.0731 *$ & -0.0575 \\
\hline & $(0.0434)$ & $(0.0620)$ \\
\hline \multirow[t]{2}{*}{ 2002-2007 expansion } & 0.0368 & 0.0535 \\
\hline & $(0.0434)$ & $(0.0546)$ \\
\hline \multirow[t]{2}{*}{ 2007-2009 recession } & $-0.157 * * *$ & 0.0821 \\
\hline & $(0.0463)$ & $(0.106)$ \\
\hline \multirow[t]{2}{*}{ 2009-2016 expansion } & $-0.227 * * *$ & $-0.174 *$ \\
\hline & $(0.0456)$ & $(0.102)$ \\
\hline \multirow[t]{2}{*}{ 1976-1980 expansion x $\Delta$ unemployment } & & 0.0202 \\
\hline & & $(0.0498)$ \\
\hline \multirow{2}{*}{ 1980-1982 recession x $\Delta$ unemployment } & & $-0.0218 * *$ \\
\hline & & $(0.00999)$ \\
\hline \multirow[t]{2}{*}{ 1982-1990 expansion x $\Delta$ unemployment } & & 0.0110 \\
\hline & & $(0.0323)$ \\
\hline \multirow[t]{2}{*}{ 1990-1991 recession x $\Delta$ unemployment } & & -0.0162 \\
\hline & & $(0.0270)$ \\
\hline \multirow[t]{2}{*}{ 1991-2000 expansion x $\Delta$ unemployment } & & 0.00607 \\
\hline & & $(0.0149)$ \\
\hline \multirow[t]{2}{*}{2001 recession $\mathrm{x} \Delta$ unemployment } & & -0.00233 \\
\hline & & $(0.0248)$ \\
\hline \multirow[t]{2}{*}{ 2002-2007 expansion x $\Delta$ unemployment } & & 0.00385 \\
\hline & & $(0.0251)$ \\
\hline \multirow[t]{2}{*}{ 2007-2009 recession $\mathrm{x} \Delta$ unemployment } & & $-0.0431 * *$ \\
\hline & & $(0.0217)$ \\
\hline \multirow[t]{2}{*}{ 2009-2016 expansion x $\Delta$ unemployment } & & 0.00928 \\
\hline & & $(0.0253)$ \\
\hline Observations & 458 & 458 \\
\hline R-squared & 0.439 & 0.421 \\
\hline
\end{tabular}

${ }^{1}$ Not all states experienced the 1990-1991 recession.

Note: Robust standard errors in parenthesis. ${ }^{* * *} \mathrm{p}<0.01,{ }^{* *} \mathrm{p}<0.05,{ }^{*} \mathrm{p}<0.1$

Source: Authors' calculations. 
Table A2. Regression Results of TFR on Select State-level Characteristics for 2001-2003 and 2014-2016

\begin{tabular}{|c|c|c|c|c|c|c|c|c|}
\hline & \multicolumn{4}{|c|}{$2001-2003$} & \multicolumn{4}{|c|}{ 2014-2016 } \\
\hline & $(1)$ & $(2)$ & $(3)$ & $(4)$ & $(5)$ & $(6)$ & $(7)$ & $(8)$ \\
\hline Hispanic & $\begin{array}{c}0.00797 * * * \\
(0.00113)\end{array}$ & & & & $\begin{array}{l}0.00175 * \\
(0.00101)\end{array}$ & & & \\
\hline Foreign-born Hispanic & & $\begin{array}{l}-0.00410 \\
(0.00542)\end{array}$ & $\begin{array}{c}0.00191 \\
(0.00538)\end{array}$ & $\begin{array}{c}0.00668 \\
(0.00574)\end{array}$ & & $\begin{array}{c}-0.00882 * * \\
(0.00412)\end{array}$ & $\begin{array}{l}-0.00351 \\
(0.00317)\end{array}$ & $\begin{array}{l}0.000742 \\
(0.00327)\end{array}$ \\
\hline Native-born Hispanic & & $\begin{array}{r}0.0150 * * * \\
(0.00361)\end{array}$ & $\begin{array}{r}0.0123 * * * \\
(0.00277)\end{array}$ & $\begin{array}{r}0.0117 * * * \\
(0.00311)\end{array}$ & & $\begin{array}{c}0.00724 * * * \\
(0.00267)\end{array}$ & $\begin{array}{c}0.00440 * * * \\
(0.00148)\end{array}$ & $\begin{array}{r}0.00336 * * \\
(0.00161)\end{array}$ \\
\hline Black & $\begin{array}{l}-0.00117 \\
(0.00139)\end{array}$ & $\begin{array}{r}-0.000444 \\
(0.00146)\end{array}$ & $\begin{array}{l}8.23 \mathrm{e}-06 \\
(0.00129)\end{array}$ & $\begin{array}{r}-0.000784 \\
(0.00136)\end{array}$ & $\begin{array}{r}-0.00276 * * \\
(0.00112)\end{array}$ & $\begin{array}{l}-0.00178 \\
(0.00124)\end{array}$ & $\begin{array}{l}-0.00137 \\
(0.00108)\end{array}$ & $\begin{array}{l}-0.00149 \\
(0.00111)\end{array}$ \\
\hline College or more & $\begin{array}{c}-0.0136 * * * \\
(0.00270)\end{array}$ & $\begin{array}{c}-0.0129 * * * \\
(0.00251)\end{array}$ & $\begin{array}{r}-0.00498 * * \\
(0.00235)\end{array}$ & $\begin{array}{c}-0.00466^{*} \\
(0.00254)\end{array}$ & $\begin{array}{r}-0.0141 * * * \\
(0.00204)\end{array}$ & $\begin{array}{r}-0.0135^{* * *} \\
(0.00189)\end{array}$ & $\begin{array}{c}-0.00836 * * * \\
(0.00174)\end{array}$ & $\begin{array}{r}-0.00645 * * * \\
(0.00178)\end{array}$ \\
\hline Non-church member & $\begin{array}{r}-0.000913 \\
(0.00174)\end{array}$ & $\begin{array}{l}6.26 \mathrm{e}-05 \\
(0.00183)\end{array}$ & $\begin{array}{l}0.000180 \\
(0.00161)\end{array}$ & $\begin{array}{l}0.000502 \\
(0.00177)\end{array}$ & $\begin{array}{c}-0.00654 * * * \\
(0.00130)\end{array}$ & $\begin{array}{c}-0.00579 * * * \\
(0.00127)\end{array}$ & $\begin{array}{c}-0.00358 * * * \\
(0.000989)\end{array}$ & $\begin{array}{c}-0.00324 * * * \\
(0.00114)\end{array}$ \\
\hline Female-to-male wage ratio & & & $\begin{array}{r}-0.0136 * * * \\
(0.00443)\end{array}$ & & & & $\begin{array}{r}-0.0106 * * * \\
(0.00157)\end{array}$ & \\
\hline $\begin{array}{l}\text { Female-to-male wage ratio } \\
\text { (education adj.) }\end{array}$ & & & & $\begin{array}{r}-0.00897 * * \\
(0.00389)\end{array}$ & & & & $\begin{array}{r}-0.0112 * * * \\
(0.00180)\end{array}$ \\
\hline Child cost-to-income ratio & & & $\begin{array}{c}-0.0328 * * \\
(0.0163)\end{array}$ & $\begin{array}{c}-0.0482 * * * \\
(0.0140)\end{array}$ & & & $\begin{array}{c}-0.0206 * * * \\
(0.00764)\end{array}$ & $\begin{array}{r}-0.0251 * * * \\
(0.00726)\end{array}$ \\
\hline Constant & $\begin{array}{c}2.325 * * * \\
(0.128)\end{array}$ & $\begin{array}{c}2.254 * * * \\
(0.135)\end{array}$ & $\begin{array}{c}3.051 * * * \\
(0.326)\end{array}$ & $\begin{array}{c}2.767 * * * \\
(0.293)\end{array}$ & $\begin{array}{c}2.639 * * * \\
(0.102)\end{array}$ & $\begin{array}{c}2.569 * * * \\
(0.100)\end{array}$ & $\begin{array}{c}3.116^{* * *} \\
(0.118)\end{array}$ & $\begin{array}{c}3.044 * * * \\
(0.126)\end{array}$ \\
\hline Observations & 153 & 153 & 153 & 153 & 153 & 153 & 153 & 153 \\
\hline R-squared & 0.426 & 0.450 & 0.549 & 0.509 & 0.459 & 0.485 & 0.608 & 0.596 \\
\hline
\end{tabular}

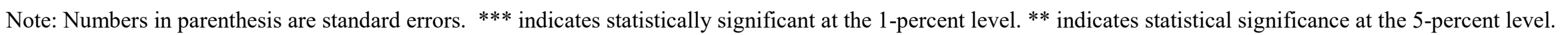

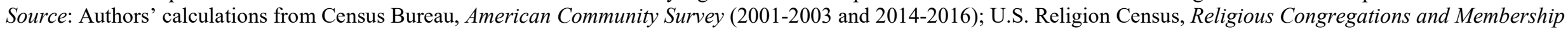

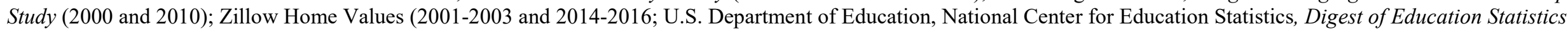

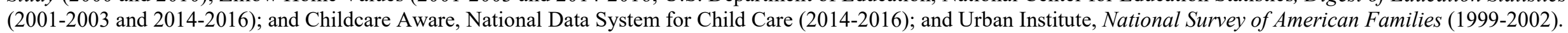


Table A3. Results from Oaxaca-Blinder Decomposition

\begin{tabular}{lc|c}
\hline Variable & Change in proportions & Change in coefficients \\
\hline Share foreign-born Hispanic & 0.03258 & 0.03258 \\
& $(0.0367)$ & $(0.0367)$ \\
Share native-born Hispanic & $0.08195^{* *}$ & $0.08195^{* *}$ \\
& $(0.0348)$ & $(0.0348)$ \\
Share Black & 0.00880 & 0.00880 \\
& $(0.0201)$ & $(0.0201)$ \\
Share college or more & $0.05174^{* * *}$ & 0.05174 \\
& $(0.1047)$ & $(0.1047)$ \\
Share non-church members & 0.18927 & $0.18927 * *$ \\
& $(0.0781)$ & $(0.0781)$ \\
Ratio of female-male wages & $0.14484^{* * *}$ & 0.14484 \\
Ratio of child cost to income & $(0.2514)$ & $(0.2514)$ \\
& $-0.09169^{* *}$ & -0.09169 \\
& $(0.0673)$ & 0.03258 \\
\hline
\end{tabular}

Note: Numbers in parenthesis are standard errors. *** indicates statistically significant at the 1-percent level, ** indicates statistically significant at the 5-percent level.

Source: Authors' calculations from Census Bureau, American Community Survey (2001-2003 and 2014-2016); U.S. Religion Census, Religious Congregations and Membership Study (2000 and 2010); Zillow Home Values (20012003 and 2014-2016; U.S. Department of Education, National Center for Education Statistics, Digest of Education Statistics (2001-2003 and 2014-2016); and Childcare Aware, National Data System for Child Care (2014-2016); and Urban Institute, National Survey of American Families (1999-2002). 


\section{RECENT WORKING PAPERS FROM THE CENTER FOR RETIREMENT RESEARCH AT BOSTON COLLEGE}

Will Fewer Children Boost Demand for Formal Caregiving?

Gal Wettstein and Alice Zulkarnain, March 2019

The Relationship Between Occupational Requirements and SSDI Activity

Matthew S. Rutledge, Alice Zulkarnain, and Sara Ellen King, February 2019

How Does Contingent Work Affect SSDI Benefits?

Matthew S. Rutledge, Alice Zulkarnain, and Sara Ellen King, February 2019

Do Pension Cuts for Current Employees Increase Separation?

Laura D. Quinby and Gal Wettstein, January 2019

Competition, Asymmetric Information, and the Annuity Puzzle: Evidence from a Government-Run Exchange in Chile

Gastón Illanes and Manisha Padi, January 2019

Failure to Contribute: An Estimate of the Consequences of Non- and Underpayment of Self-Employment Taxes by Independent Contractors and On-Demand Workers on Social Security

Caroline Bruckner and Thomas L. Hungerford, January 2019

How Much Income Do Retirees Actually Have? Evaluating the Evidence from Five National Datasets

Anqi Chen, Alicia H. Munnell, and Geoffrey T. Sanzenbacher, November 2018

The Minimum Wage and Incentives for Full-Time Work Under the Social Security Retirement Earnings Test

Gary V. Engelhardt, October 2018

Would Greater Awareness of Social Security Survivor Benefits Affect Claiming Decisions? Anek Belbase and Laura D. Quinby, October 2018

How Does Delayed Retirement Affect Mortality and Health?

Alice Zulkarnain and Matthew S. Rutledge, October 2018

How Have Automation and Trade Affected the Taxable Share of Covered Earnings? Gal Wettstein, Matthew S. Rutledge, and Wenliang Hou, October 2018

All working papers are available on the Center for Retirement Research website (https://crr.bc.edu) and can be requested by e-mail (crr@bc.edu) or phone (617-552-1762). 